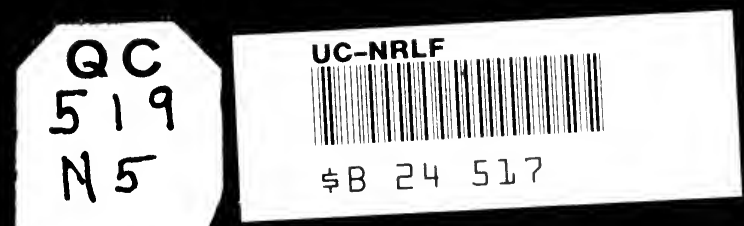




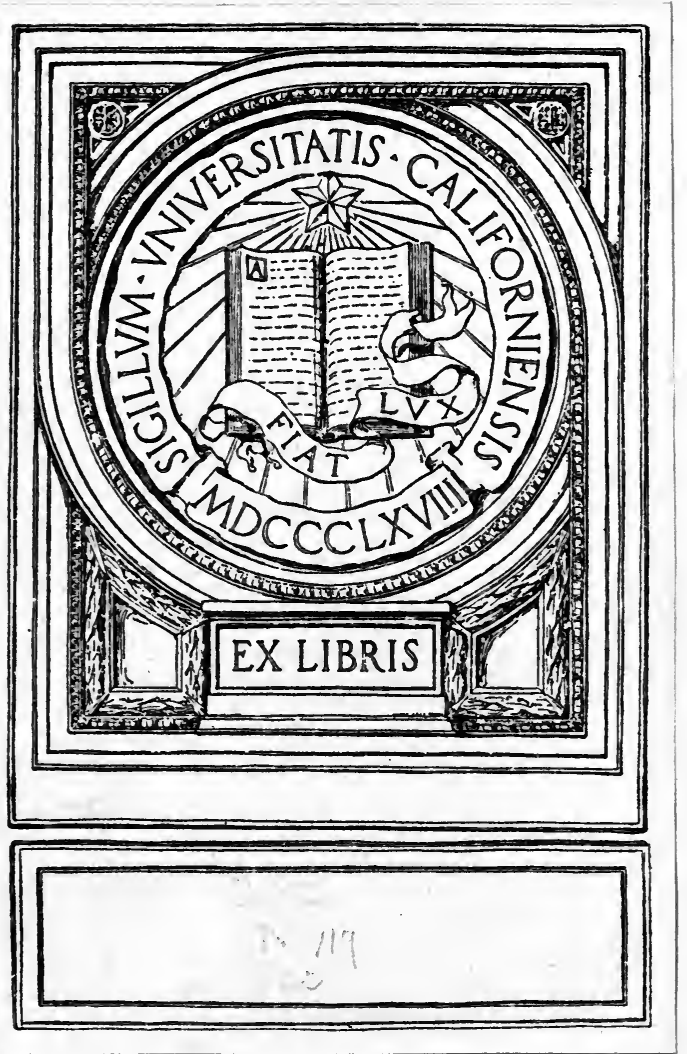




EXPERIMENTAL STUDIES

IN

ELECTRICITY AND MAGNETISM

N.I P H E R 



\section{Experimental Studies}

IN

\section{Electricity and Magnetism}

BY

FRANCIS E. NIPHER

WITH 9 PLATES, 29 TEXT FIGURES

PHILADELPHIA

P. BLAKISTON'S SON \& CO. 1012 WALNUT STREET 
Copyright, iqi4, by Fralicis E. Nipher

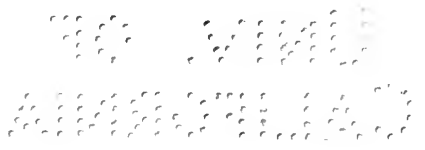




\section{INTRODUCTION}

The published papers of Professor Nipher bearing upon the nature of the electric discharge contain much evidence upon views which have long been under consideration. Thìs evidence was necessarily more or less fragmentary in character, as it appeared in successive papers in the Transactions of a learned society. While calling upon him recently in his laboratory, I advised him to present his work to the public in book form. I consider it of importance that it should receive attention from scientific men, and it will certainly be of interest to the general reader.

Thomas R. Lyle, F. R. S.

The University, Melbourne, Australia. 



\section{ERRATA}

Page 17 , line 10 from bottom, for "come" read "came."

Page 50, line 3 from top, for "service" read "device."

Page 73, first column, line 17 from bottom, for "steamers" read "streamers."

\section{FOR THE ONE- CTRICITY}

to prepare a paper for ; of Arts and Science, ject assigned by the ), was "Present Prob1e problems which was arge. A consideration ; trongly favor the onenuid tneory. since tnal tmine nearry an of my time has been devoted to a search for additional evidence of an experimental character which would be readily explainable by one of these theories and not by the other. Most of this work has been published by the Academy of Science of St. Louis. ${ }^{1}$ Recently several friends have strongly advised that this evidence should be presented to the public in a more logically connected form than was possible in the original papers. This little volume is a response to such requests.

When a metal sphere, suspended on a silk thread, is placed between the discharge knobs of an electrical machine, it oscillates to and fro between the knobs. It is alternately attracted by and then repelled from each terminal.

Assume now that the space between the knobs is occupied only by air under atmospheric conditions. Each molecule of air is then seeking to behave as did that metal sphere. It is manifestly impossible for any one of them to do this. A stream of molecules is repelled from each terminal toward the opposite one. They mingle with each other. Electrically these opposing streams are friendly, but mechanically they are in pronounced opposition to each other.

1 Trans. Vol. XIX, No. I, pp. I-20, with Io Plates, I9ro.

Vol. XIX, No. 4, pp. 57-72, with 8 Plates, I9Io.

Vol. XX, No. I, pp. I-I6, with 6 Plates, I9I I.

Vol. XXI, No. 3, pp. 79-87, with I Plate, I9I 2.

Vol. XXII, No. 2, pp. 59-65, with 2 Plates, I9I3.

Vol. XXII, No. 4, pp. ro9-I 24, with 4 Plates, I9r3. 



\section{EXPERIMENTAL EVIDENCE FOR THE ONE- FLUID THEORY OF ELECTRICITY.}

In the summer of 1903 I was requested to prepare a paper for presentation to the International Congress of Arts and Science, held in St. Louis during rgo4. The subject assigned by the President of the Congress, Simon Newcomb, was "Present Problems in the Physics of Matter." One of the problems which was considered was the nature of electrical discharge. A consideration of phenomena then well known seemed to strongly favor the onefluid theory. Since that time nearly all of my time has been devoted to a search for additional evidence of an experimental character which would be readily explainable by one of these theories and not by the other. Most of this work has been published by the Academy of Science of St. Louis. ${ }^{1}$ Recently several friends have strongly advised that this evidence should be presented to the public in a more logically connected form than was possible in the original papers. This little volume is a response to such requests.

When a metal sphere, suspended on a silk thread, is placed between the discharge knobs of an electrical machine, it oscillates to and fro between the knobs. It is alternately attracted by and then repelled from each terminal.

Assume now that the space between the knobs is occupied only by air under atmospheric conditions. Each molecule of air is then seeking to behave as did that metal sphere. It is manifestly impossible for any one of them to do this. A stream of molecules is repelled from each terminal toward the opposite one. They mingle with each other. Electrically these opposing streams are friendly, but mechanically they are in pronounced opposition to each other.

1 Trans. Vol. XIX, No. I, pp. I-20, with 1o Plates, I9Io.

Vol. XIX, No. 4 , pp. 57-72, with 8 Plates, I9 Iо.

Vol. XX, No. I, pp. I-I6, with 6 Plates, I9II.

Vol. XXI, No. 3, pp. 79-87, with I Plate, I9I 2.

Vol. XXII, No. 2, pp. 59-65, with 2 Plates, I9I3.

Vol. XXII, No. 4, pp. I09-I24, with 4 Plates, I9I3. 
The machine used for this work was a large four-plate influence machine. The arrangement best adapted to produce the results to be described is shown in Fig. I. The machine terminals are each connected with external knobs $\mathrm{A}$ and $\mathrm{A}^{1}$, between which are smaller discharge terminals, having smaller knobs at each end. These discharge rods are movable. Small spark gaps may thus be made at $a$ and $a^{1}$.

For the work to be first described, the condensers were removed. A sheet of copper CC mounted on insulating supports was placed midway between the discharge terminals. Between the positive terminal and the copper plate a large diverging brush discharge appears. Its form depends somewhat upon the length of the minute gaps at $a$ and $a^{1}$. It extends over an area 5 or $6 \mathrm{~cm}$.

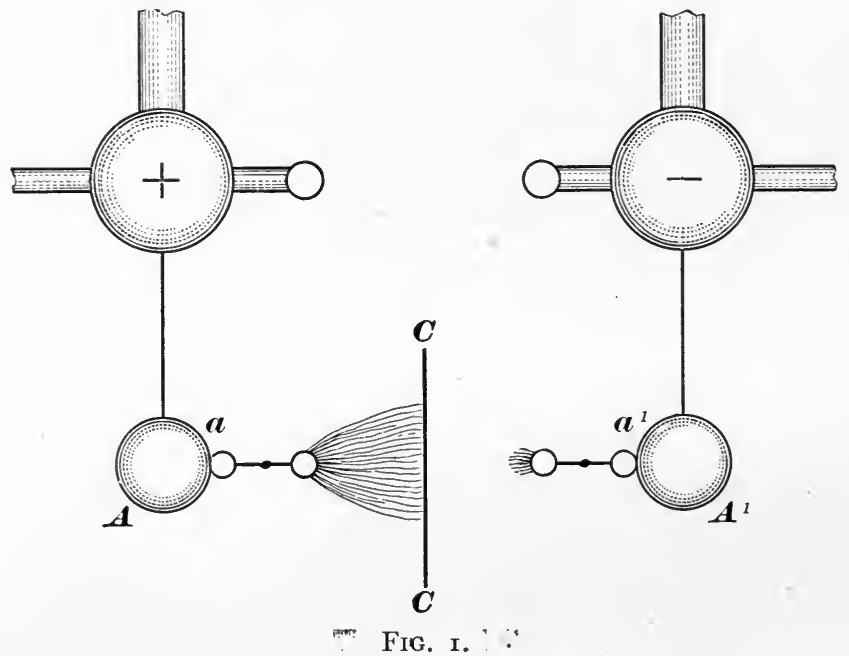

in "diameter upon the copper plate. The distance between the plate and the positive terminal was about 6 or $7 \mathrm{~cm}$.

The small knob forming the negative termínal was covered with the negative glow, but between this glow and the copper plate the space was absolutely dark. It was, however, evident that there was an active discharge across this dark space if there was a small gap at either $a$ or $a^{1}$.

A small windmill having vanes of thin mica mounted in a hub of hard rubber, and turning on pivots of vulcanized fiber will revolve when placed in either gap. In the positive column, the 
air is thus shown to be moving toward the plate, and from the positive terminal. In the dark space the air is moving in the opposite direction. In the positive column the rotation was about like that which could be produced by walking with the wind-

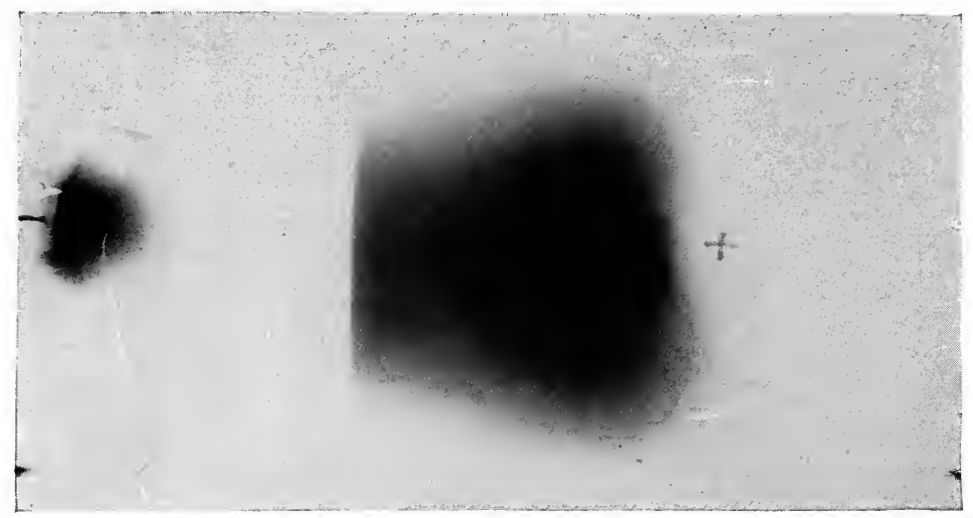

Fig. 2.

mill in still air with a velocity of $1.5 \mathrm{~m}$. per second. In the dark space the speed was somewhat less.

If the copper plate is moved toward the negative terminal, the luminous column on the positive side becomes longer. It still terminates on the plate. If it is moved in the opposite direction,

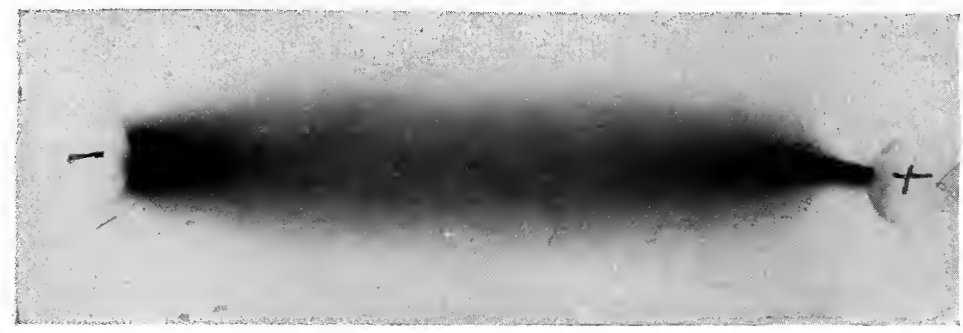

FIG. 3.

the dark space becomes longer. It follows the plate up to the positive terminal.

A camera photograph of the negative glow and the luminous positive column is presented in Fig. 2. A large copying camera was used. An exposure of ${ }_{5} 5$ minutes, was made in a dark room. 
The metal plate $C C$ of Fig. I was removed. A minute sparkgap was made at $a^{1}$. The contact at $a$ was made as complete as possible, so that no luminous point is seen at this contact. The discharge then swept through the entire spark-gap of about $I_{5} \mathrm{~cm}$. The photograph of this luminous column as taken by the camera

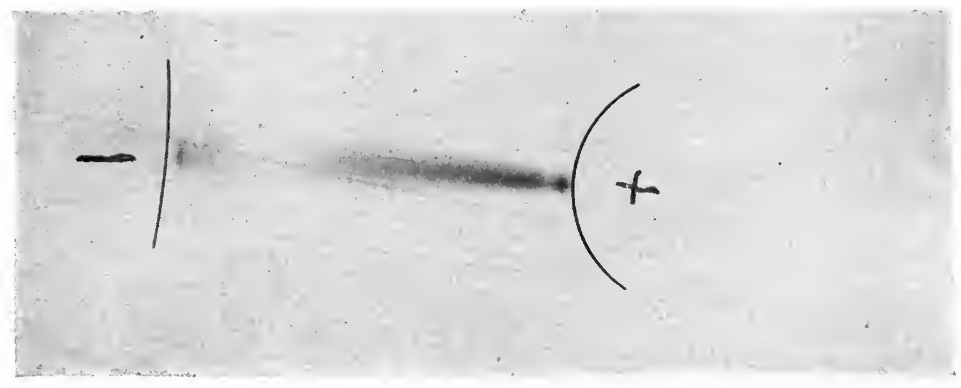

FIG 4.

is shown in Fig. 3. The exposure was about 5 minutes. The mica windmill shows a feeble wind from the positive terminal. If the gap at $a^{1}$ is made somewhat larger, the discharge is then filled throughout with small disruptive sparks, and the windmill will not operate. If the gap $a^{1}$ is made still longer appearing, as

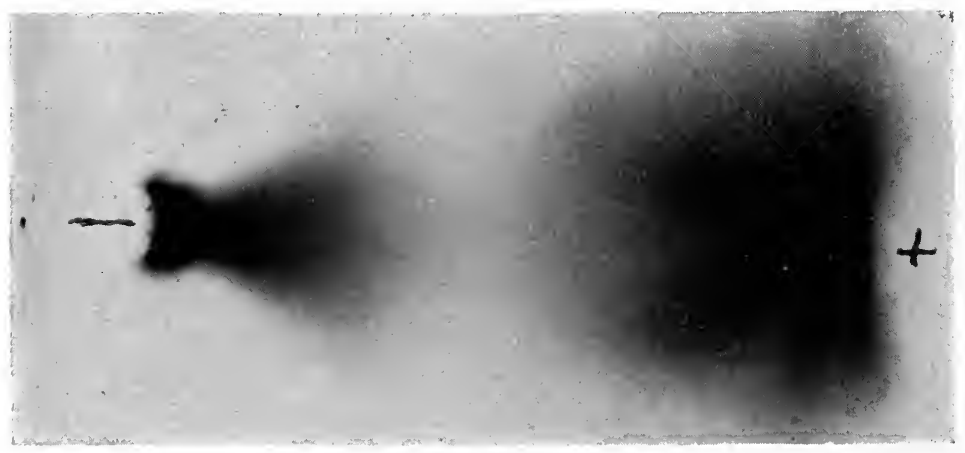

FIG. 5.

seen in Fig. 4, a strong positive wind causes the windmill to rotate so rapidly that its vanes are invisible. ${ }^{1}$ This wind sweeps through the entire gap. The discharge is not then disruptive in character.

${ }^{1}$ Fig. 4 is from a photograph of this gap, $a^{1}$, but the outlines of the knobs were only faintly visible. They are drawn in ink. 
If the gap at $a^{1}$ is closed and that at $a$ is opened, the luminous streamers forming the positive column are beaten back by a blast of air from the negative terminal. The mica windmill shows that the negative wind now sweeps the entire gap. Fig. 5 is a camera photograph of the discharge. The slightest change in the length of the spark-gaps $a$ and $a^{1}$ produces marked changes in the form and character of the discharge through the long gap. Such changes are attended by variation in the pitch of musical tones which accompany the discharge. When both of the gaps $a$ and $a^{1}$ are closed the negative glow is still visible, but the luminous column is only very faintly visible.

The copper plate $C C$ of Fig. I was again placed in position

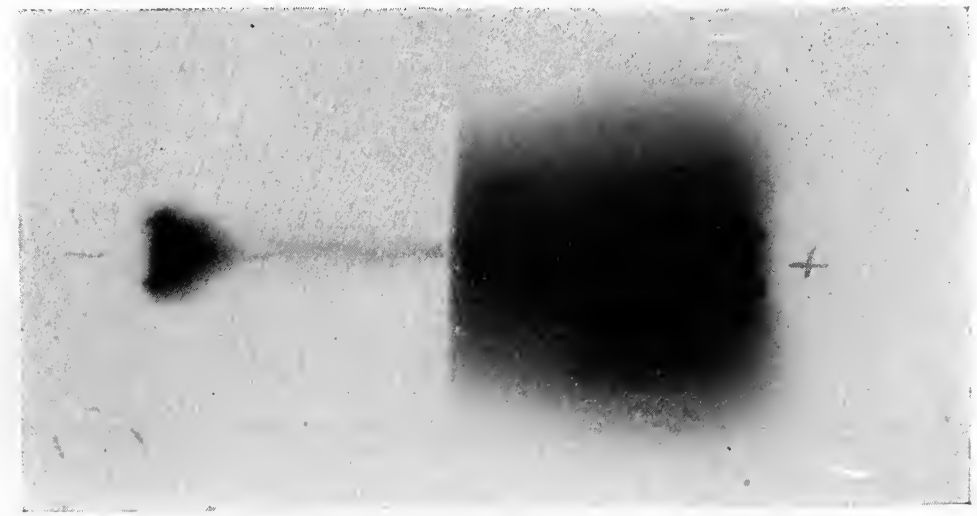

FIG. 6.

as in the discharge shown in Fig. 2. A hole having a diameter of about $5 \mathrm{~mm}$. was made in the copper plate.

The positive column on the positive side of the plate was not appreciably changed in form by the presence of this hole, but it then extended through the hole to the negative glow, as seen in the two Figs. 6 and $6 a$. The relative luminosity of the canal ray passing through this hole, and of the positive column of which it is a prolongation, depends upon the lengths of the oscillation gaps $a$ and $a^{1}$. In these gaps there is a continuous surging to and fro of air molecules. It is evidently a time alternation of convection and conduction discharge. In the one case the negative corpuscles are carried across the gap by super-charged 
molecules. This is a dark discharge. When these molecules return they have lost not only the excess but a part of their own normal charges. They then form a conductor, through which a

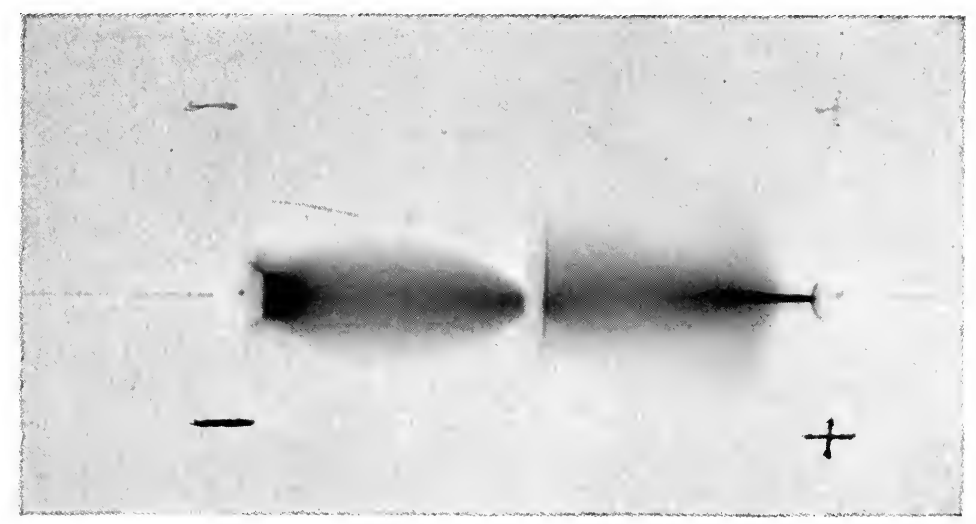

FIG. $6 a$.

luminous transfer by conduction takes place. These vibrations show their presence by musical tones of high pitch. The pitch of these notes rises as the gaps $a$ and $a^{1}$ are made shorter. The sounds cease when these gaps are closed. In Fig. $6 a$, a minute

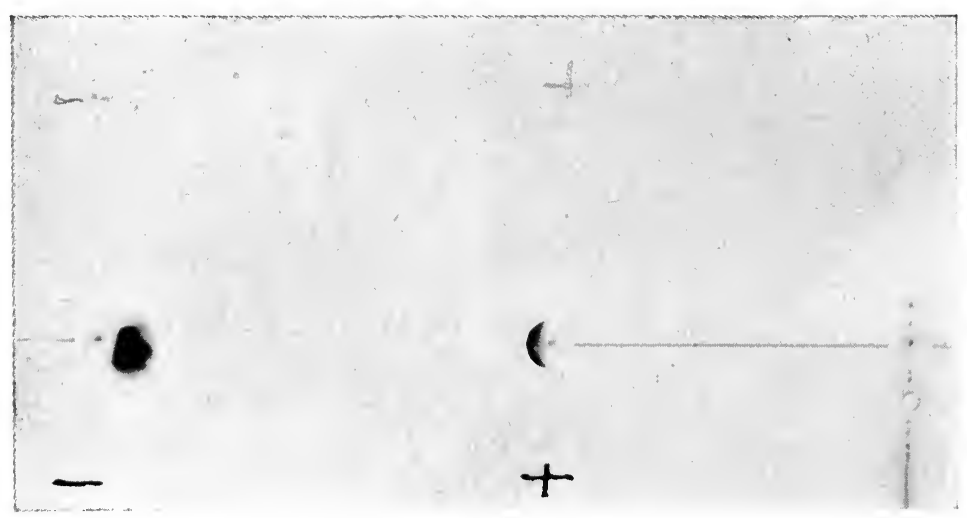

FIG. 7 .

gap of less than a mm. existed in the negative approach line at $a^{1}$. In Fig. 6 this gap was closed and a similar gap was made at $a$ in the positive line. In Fig. 7 both gaps were closed. In each 
case a flash light was used at the end of a 5-minute exposure, in order to secure an image of the knobs. The diameter of the knobs was $1.8 \mathrm{~cm}$.

When both gaps $a$ and $a^{1}$ are closed and the lines leading from the machine terminals to the main gap are metallic throughout, as in Fig. 7, an active negative glow exists in front of the negative knob. The mica windmill shows that the air is being urged across the negative dark space to the copper plate. In the gap between the copper plate and the positive knob, there were no luminous streamers, but they formed when the windmill was placed in this gap, and a faint motion of the air toward the copper plate was then indicated.

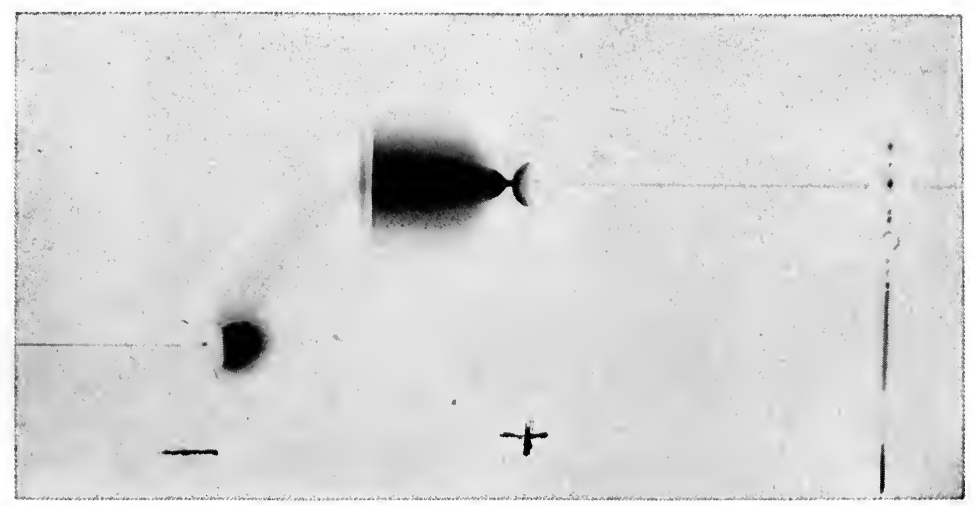

FIG. 8.

The front edge of the plate is not in focus, and its image is rather imperfectly reproduced in the original, and does not appear in Fig. 7 .

In Fig. 7 a strongly marked glow is shown on the surface of the positive knob. It covers the hemisphere which faces the copper plate. This glow differs from the negative glow at the other knob. It gives the front of the knob the appearance of being at a red heat. Scintillations are occasionally visible over this luminous surface. They are perhaps the beginnings of drainage streamers. It seems evident that air molecules in contact with this luminous part of the knob are delivering corpuscles to the knob, but the drainage luminescence does not extend beyond the layer in close 
contact with the knob. If the contacts at either $a$ or $a^{1}$ are disturbed so that any luminous effects exist at these gaps, this positive glow partly or wholly disappears and one or more luminous streamers shoot out from the positive knob. The drainage inflow to the positive terminal is then through and along these conducting channels. If the gap at $a$ in the positive line is slightly increased in length, the luminous streamers appear in arc-like forms from points around the central line of discharge. These streamers are continually vibrating as in the case when convection and conduction winds in opposite directions exist side by side.

In Fig. 8 the discharge knobs were displaced laterally. The hole in the copper plate was opposite the positive knob, and in

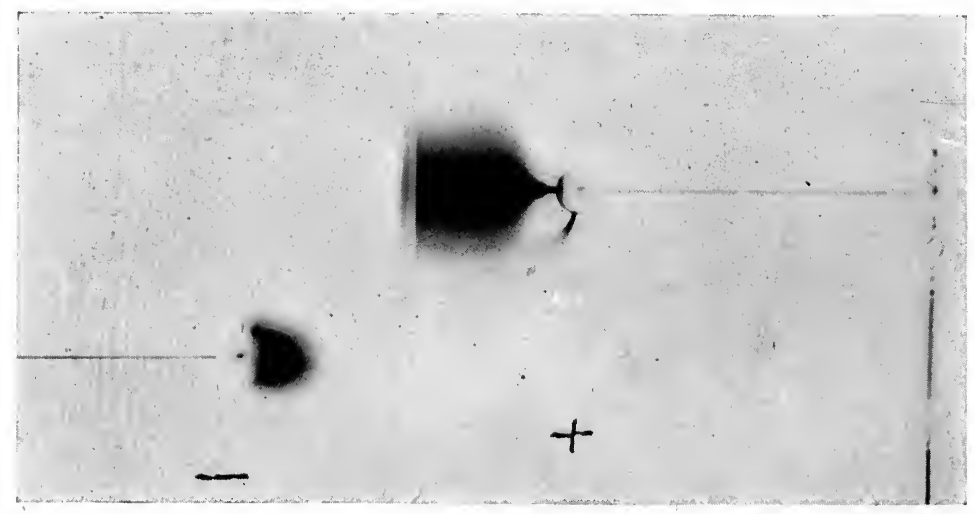

FIG. 9.

the central part of the cone-shaped positive column. It will be observed that the canal ray passing through this hole turns toward and extends to the negative glow. A flash light followed this exposure. In Fig. 9 the conditions were precisely similar, except that the hole in the copper sheet was opposite the negative terminal. The luminous cone has the same form as before. It will be observed that the discharge from the negative knob across the dark space to the hole in the copper plate, has an influence upon the drainage to the positive terminal. A secondary positive column forms at the lowest point on the positive knob, and curves toward the hole in the copper plate.

In Fig. Io the discharge terminals are in line with each other 


\section{Shadow Effects}

but the copper plate was displaced. The canal ray was partly obstructed by a small disc of copper, mounted upon the end of a glass tube.

Fig. I I shows the shadow in the positive column made by a

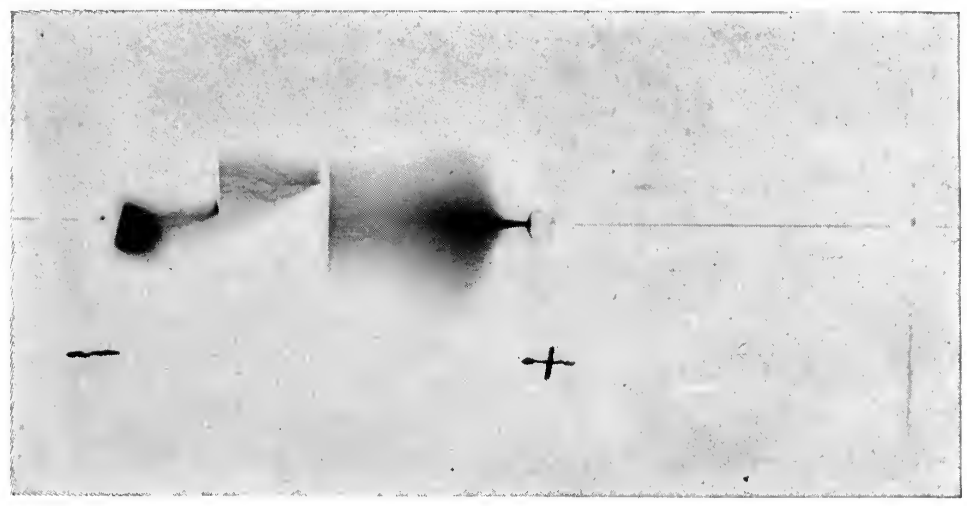

FIG. IO. :

glass tube placed midway between the positive knob, and the copper plate. The end of the tube faces the camera. There was no hole in the copper plate. It will be observed that the shape of the shadow is somewhat modified by the air current which drifted around the obstruction.

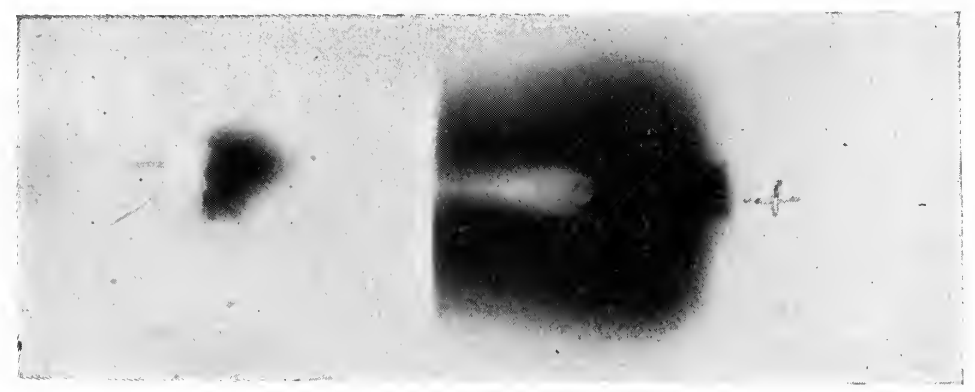

FIG. II.

A couple of two-gallon Leyden jars were then connected with the machine terminals and the experiments shown in Figs. 8 and 9 were repeated. Five loud disruptive discharges are shown in Fig. I2. On the negative side of the copper plate these dis- 
charges with one exception followed along the line of the canal ray shown in Fig. 8. They passed through the hole in the copper plate.

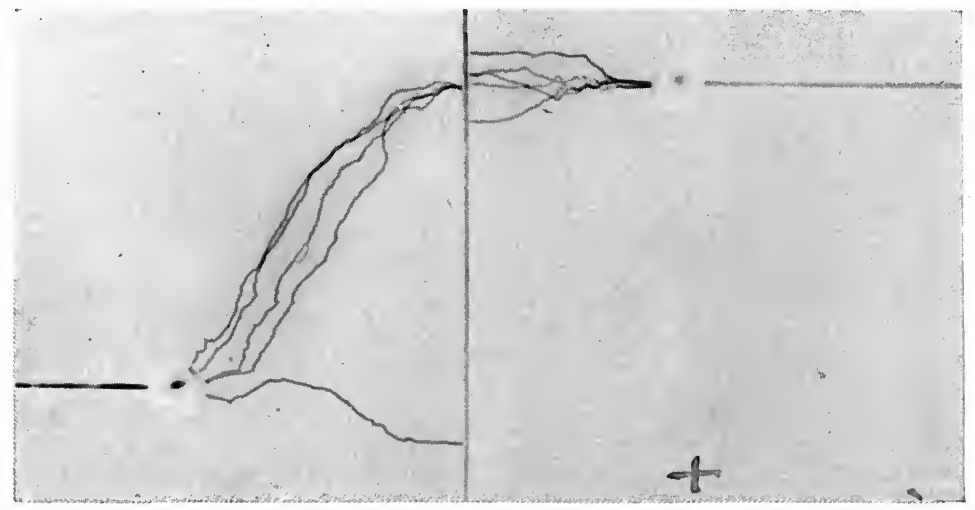

FIG. I2.

In Fig. I3 the conditions were only changed by hanging a thin strip of paper over the top of the copper plate. This paper covered the hole, and prevented the passage of the canal ray.

In Fig. I4, the conditions of Fig. 9 were reproduced. The

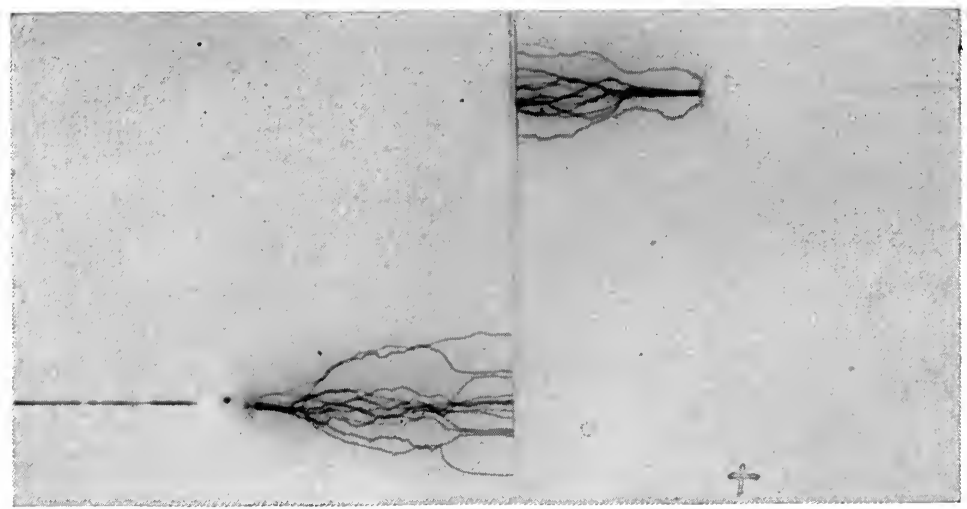

FIG. I3.

hole was open, but it was opposite the negative discharge knob. The discharge rods were then placed in line with each other, as in Fig. 2. The distance between the knobs was about $13 \mathrm{~cm}$. The 
Leyden jars were sțill attached to the machine terminals. The copper plate, having no opening in it was hung between the spark knobs on long silk threads. The plate moved into a position of stable equilibrium at a distance of 3 or $4 \mathrm{~cm}$. from the negative knob. In this position loud spark discharges passed through the plate as readily as they would pass when it was removed. The dark space still existed between the plate and the negative glow. Moving the plate farther from the negative terminal, the discharges ceased. A position could be found where a change of a fraction of a $\mathrm{mm}$. in the position of the metal plate would produce a radical change in the discharge. In one position a torrent of loud sparks passes. In the other position disruptive discharge ceases.

When the conditions as described in connection with Fig. 4

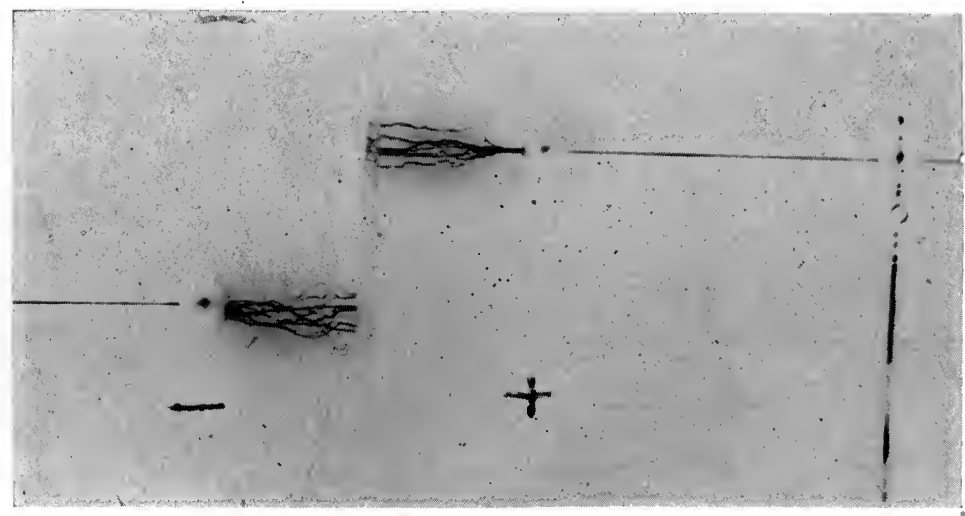

FIG. I4.

are imposed, the same results may be secured by placing the metal plate in the smaller gap $a^{1}$.

When the main spark gap is made long enough so that sparks will still pass between the knobs, but the limit is being approached, the interposition of a copper plate of sufficient size will cut off the drainage column as has been shown in previous figures. It then appears at the edges and corners of the interposed plate. In Fig. I 5 these conditions are shown. The luminous column curved toward the negative knob from the edge of the plate. Just before the spark passed it had nearly reached the negative glow. The disruptive discharge then passed along this drainage channel from 
the edge of the insulated copper plate to the negative knob. The plate was near enough to the positive terminal, so that it might be considered a part of that terminal. The disruptive discharge does not follow the line of least distance. It follows the line of least resistance. The conditions are similar to those represented in Fig. I2. If the exposure had ceased just before the passing of the disruptive discharge, the positive column and negative glow only would have been represented, as in Fig. 8.

The evidence thus far furnished appears to indicate conclusively, that the positive column is a channel in which the air is in a condition of conduction. It is a drainage channel. The positive terminal of the machine is an exhaust terminal. Mole-

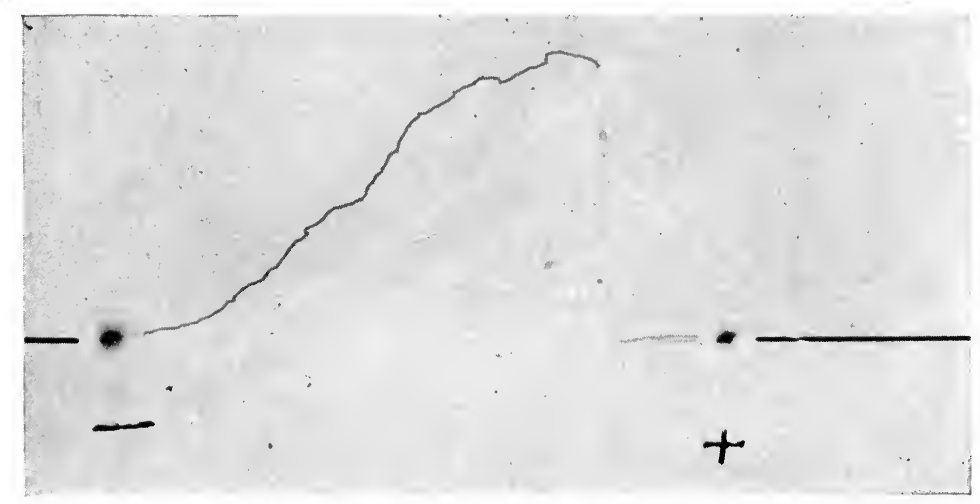

FIG. I5.

cules of air in contact with it deliver negative corpuscles to it. Normally they are moving with an average velocity of about I 400 feet per second. They are also oscillating to and fro in the short spark-gaps. The corpuscular nebula within the metal conductors is set into a rhythmical vibration. These conditions result in a delivery of negative corpuscles to the positive terminal by some of the gas molecules which collide with it at the instant when the terminal is in a condition of maximum exhaust. The same conditions result in a rhythmical issue from the negative terminal, of negative corpuscles, which are loaded upon the air molecules then in collision with that terminal."

It is sometimes stated that $\mathrm{X}$-rays and ultra violet light 
ionize the air and put it in a condition of conduction. The evidence that it is in this condition is that an electrometer, the metal parts of which have either an excess or a deficiency of negative corpuscles, will when placed in air thus ionized, return to the normal condition. This air thus ionized is not in the condition of air within the positive column. In air ionized by $\mathrm{X}$-rays, the average negative charge per molecule, is the same as before the ionization. An overcharged molecule will deliver its excess of negative fluid, to the particular molecule which it has robbed, to any other molecule, or to a metal terminal in a like condition. The air which is being repelled from a negative terminal, would also deliver negative corpuscles to an electrometer having less than the normal charge of the negative fluid. This would not indicate that it is in a condition of conduction,

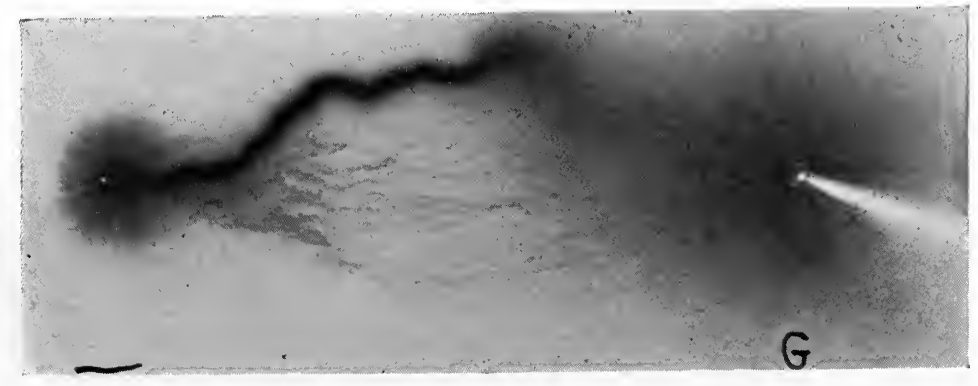

FIG. I6.

in the sense in which that word is used in connection with the positive column.

An illustration of what is referred to above as a condition of conduction is given in Fig. I6. This is a reproduction of a spark discharge over the film of a photographic plate. Two pin-heads forming terminals rested upon the film. The points of the pins were soldered to the ends of copper wires, one of which was connected to the negative terminal of the infuence machine. This line contained a small spark-gap of 2 or $3 \mathrm{~mm}$. The other wire was grounded. The pin-head terminals were about $7 \mathrm{~cm}$. apart. The plates of the machine were rotated very slowly for about half a minute. In the presence of the negative terminal the a ir around the grounded pin-head was drained of negative corpus- 
cles. It was put into a condition of conduction. The velocity of rotation of the machine was then increased, and a disruptive discharge was made to pass between the pin-heads. The air around the negative pin-head was evidently not in a condition of conduc-

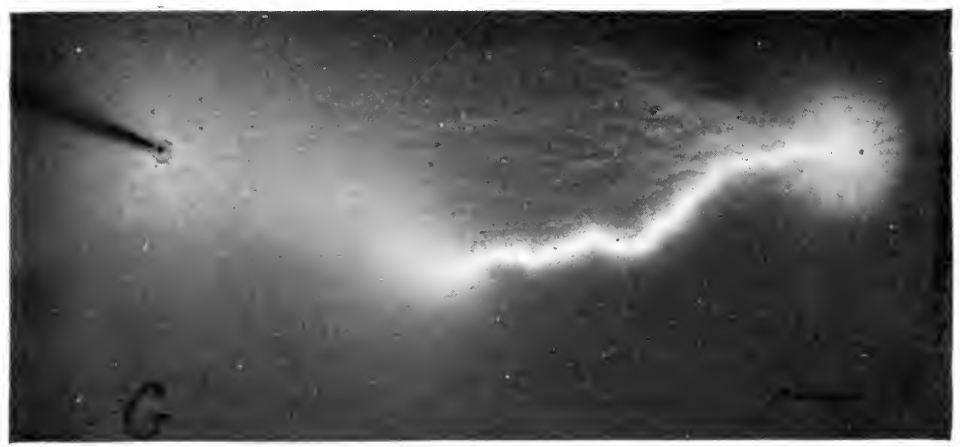

FIG. I 7 .

tion. A break-down of the air was there formed. The muzzle of the discharge channel thus formed was about equidistant from the pin-heads. A volley of negative corpuscles issued from this muzzle. Within the conduction region around the grounded pin-head there

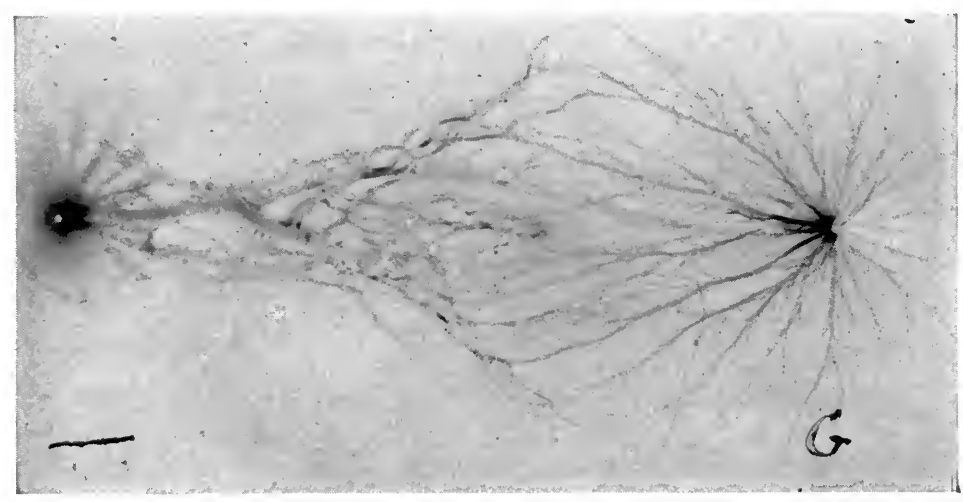

FIG. 18.

is no definite outline for the discharge. It was diffused into the conduction region around the pin-head. That the shadow effect produced by the lowest parts of the rounded pin-head was not due to protection from luminous fogging, is made clear by the form of 
the disruptive part of the discharge, and the direction of the shadow. In many previous attempts to secure this result, the discharge was practically along the line joining the two pin-heads. and the real explanation of this shadow effect was left in doubt.

Fig. $I 7$ is a reproduction of a print from the original plate Fig. I6 is a reproduction of the original plate.

Fig. 18 is a reproduction of a plate in which the operation described in connection with Figs. I 6 and I 7 was arrested just before the disruptive discharge. When the plate was exposed for a few seconds only, the effect of the negative glow would be appreciable. Short drainage lines would also appear around the

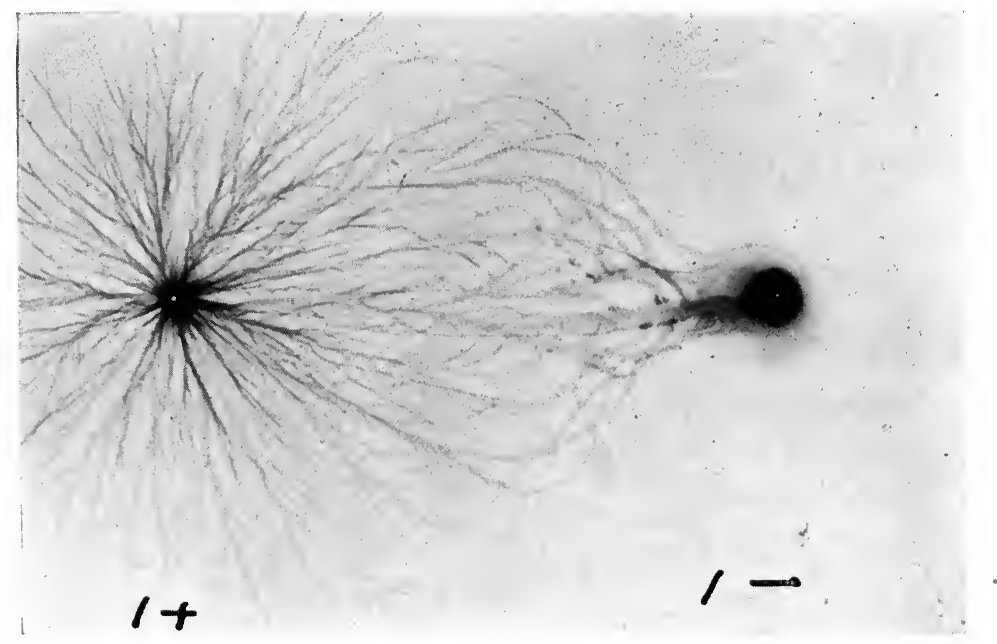

FIG. I9.

grounded pin-head. As the time of exposure was increased, the drainage lines became longer. It was only after many attempts that the result shown in Fig. I8 was obtained. It was found that a disruptive discharge usually occurred, as soon as the drainage lines had reached the negative glow.

When the pin-head forming the drainage terminal is connected with the positive terminal of the influence machine, as in Fig. I9, the drainage lines are much more strongly marked. In Fig. I9 a single spark was sent across two minute gaps at the machine terminals. These gaps were between 3 and $4 \mathrm{~mm}$. in 


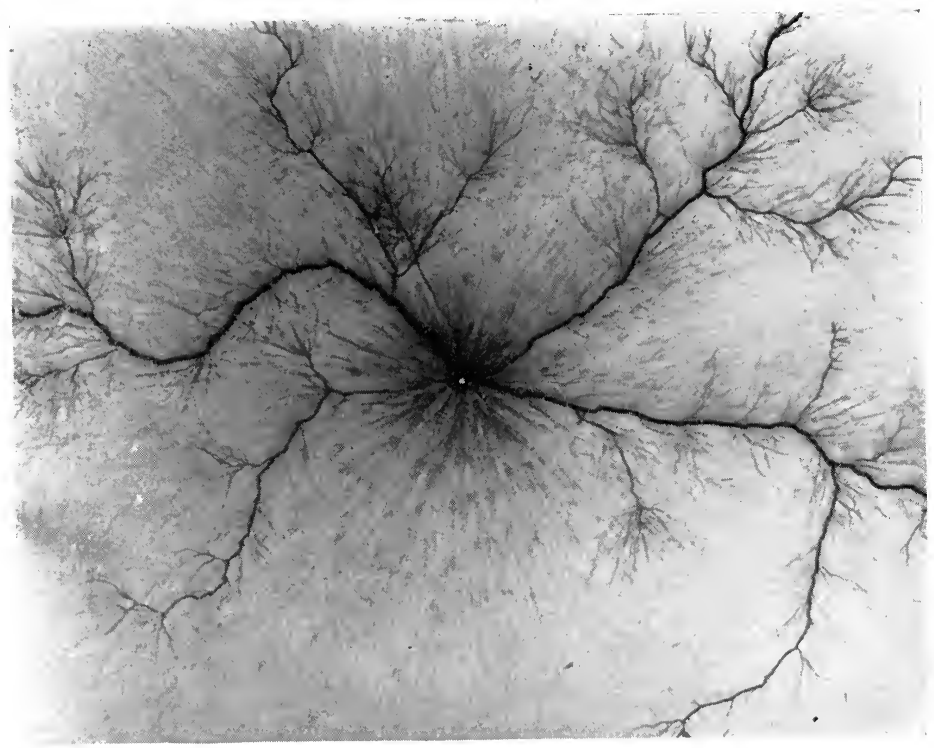

Fig. 20.-The Overcharged Cloud. An inflow of the negative fluid to the main discharge channel, whose end is seen at the middle of the plate.

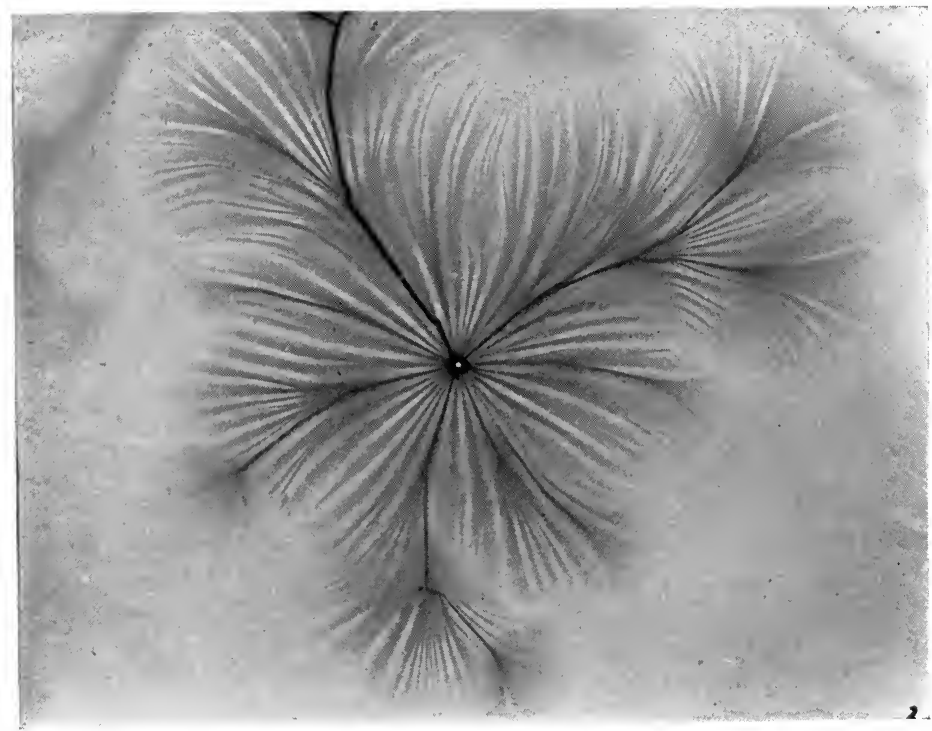

Fig. 21.-The Outflow into the Cloud which has less than its Normal Charge. 
length. No luminous effect was observed on the photographic plate, excepting in close proximity to the pin-heads.

Figs. 20 and $2 \mathrm{I}$ appeared in a paper in the January number of the Popular Science Monthly for I9I2. The paper was entitled, A Flash of Lightning. It was there stated that Fig. 20 represents in cross-section a view of a cloud which is overcharged with the negative fluid. The end of the long flash connecting this with the undercharged cloud, is visible at the middle of the plate. The lines on this plate resemble a system of rivers and tributaries. They elongate up-stream and drain the negative fluid into the long discharge channel, from which it flows outward into the undercharged cloud at the other end of the flash, Fig. 2I. This last-named cloud is in a condition of conduction. The discharge diffuses into it. The discharge from the first-mentioned cloud is forked lightning. The discharge into the other cloud is one form of sheet lightning. Before the flash occurred, the rain-drops falling through the overcharged cloud were all highly charged, and they repelled each other. After the discharge those drops which happened to lie in the path of some one of these tributary discharge lines, have lost their overcharge. There is then an attraction between such drops and those which were slightly outside of these drainage lines, and which are therefore still overcharged. These two groups of drops are intimately commingled, as is shown by the intricate nature of the system of drainage channels in Fig. 20. As they continue their fall to earth, they coalesce, and a brief dash of unusually large drops of rain is observed.

If these discharge figures are to be described in the language of the two-fluid theory, Fig. 20 must be called an outward positive discharge. Fig. 2 I must be called an outward negative discharge. We must say that each of these discharges come from the cloud at the opposite end of the flash.

Such an explanation seems so essentially absurd in the presence of these photographic plates, that it will not be urged.

In conclusion, however, a confession must be made. The lightning discharge here described was artificially produced. A plate-glass machine, with metal conductors terminating in pinheads took the place of the long flash of lightning. The pin-heads rested upon the centers of the two photographic films, the plates resting on large sheets of glass. There were small spark-gaps of 
about half an inch in each line, at the machine terminals. A single spark across these gaps produced a glow over the films around the pin-heads. In order to bring some of the discharge lines down into close proximity to the films, so that they would be sharply defined, copper plates were placed under each photographic plate below the sheet of glass. These copper plates were grounded or, what produces the same result, they were connected with each other. No trace of the discharge can be detected until the photographic plate is developed. With this confession, and with an apology for having misled the reader, the question may be asked, Can any one look at the lines of Fig. 20, and believe that they were produced by an outward discharge of positive electricity?

Fig. 20 shows in addition to these drainage lines radial markings which indicate the explosive conditions which exist within any mass of matter from which negative corpuscles have been suddenly drained. Molecules of air in contact with the pin-head upon which the drainage lines centered were suddenly drained of negative corpuscles. They then repelled each other, and were repelled by the pin-head. We might describe this action by saying that these positive ions are emitted from the positive terminal. We might also say that U. S. mail-carriers are emitted from inhabited houses, after they have delivered the daily mail matter. We might say that the metal sphere which has made contact with the positive terminal, becomes a positive ion, and is emitted from the positive terminal.

The Crookes tube has been telling the whole story for many years. We have understood that part of it which referred to conditions at the cathode. The negative corpuscles which were capable of operating the Crookes windmill, evidently came from within the metal forming the cathode. They were emitted from the cathode in straight lines. They did not follow the windings of the tube. Crookes found that in his partially exhausted tube, the positive column started from the positive terminal and curved to the negative terminal, wherever the positive terminal might enter the tube. The conditions were exactly those represented in Figs. 6 and 8 of this paper. In the experiment of J. J. Thomson, a tube of irregular form and having a length of about $5^{\circ}$ feet, was filled throughout with the positive column. The appearance at the cathode end was exactly the same as it would have 
been if the tube had been I foot in length. Moreover, as the air is exhausted, and the Crookes condition is approached, the positive column disappears. Finally the cathode discharge only remains. That the drainage lines elongate outward from the positive terminal is no more difficult of explanation than the fact that the channel of a stream elongates in the opposite direction from the direction of flow. If Niagara Falls should recede from Lake Ontario to Lake Erie in a fraction of a second, an observer might get the impression that there had been a "discharge" from Lake Ontario to Lake Erie. There is an explosive repulsion of air molecules from both terminals when a disruptive spark passes. In Fig. I9 the drainage lines from the positive terminal elongate toward the negative glow. But one of them responds to the mechanical effects involved in the convection of overcharged molecules. It curves around the negative glow. Electrically, the molecules which are being urged in opposite directions are friendly. Mechanically, they oppose each other.

It is evident that if matter could be drained of its negative corpuscles, each atom and each mass would repel every other atom and mass. When we attempt to do this, by connecting a mass of matter to the positive terminal of an electrical machine, we find that we can only drain the negative corpuscles from a thin surface film. Molecules within a mass of metal cooperate with each other in retaining possession of the corpuscular nebula within it. The electrical pump leaks. Drainage channels leading into the air form over the surface of the mass to be drained, and upon the positive terminal of the machine. Even under these conditions electrical corpuscles can be drained from small masises of matter in sufficient amount to cause them to repel each other.

Assume two spheres of mass $m$ and $m^{\prime}$. They attract each other with a force $K \mathrm{~mm}^{\prime} / \mathrm{r}^{2}$. Assume that the spheres are connected by means of a flexible conductor, and that negative corpuscles are pumped out of; or forced upon the two masses. A conditon will be found for which the attraction between these two masses will be a maximum. If the number of corpuscles in or on the masses be then either increased or diminished, the attraction will be less. With small masses we can easily reduce the attraction to zero, or make it negative. The attraction in dynes between these masses having radii $R_{1}$ and $R_{2} \mathrm{~cm}$., and distant from 
each other $r \mathrm{~cm}$., the matter composing them having a density $\rho$ is

$$
\mathrm{A}=\frac{\mathrm{R}_{1} \mathrm{R}_{2}}{r^{2}}\left(\frac{\mathrm{I} 6}{9} \pi^{2} \rho^{2} \mathrm{~K} \mathrm{R}_{1}{ }^{2} \mathrm{R}_{2}{ }^{2}-\mathrm{V}^{2}\right) .
$$

Here $\mathrm{K}$ is the gravitation constant and $\mathrm{V}$ is electrical potential in electrostatic units. This force will be zero when

$$
\mathrm{V}=\frac{4}{3} \pi \rho \sqrt{\mathrm{K}} \mathrm{R}_{1} \mathrm{R}_{2}
$$

For two spheres having the size of earth and moon, assuming $\rho=5.5$ for both masses, their potential must be raised to I.96 $\times{ }_{10}{ }^{17}$ volts, in order that they shall cease to attract each other. Rain-drops having radii of o.I cm. if charged to a potential of 0.003 I volt, will have no attraction for each other.

We do not know whether the potential of the earth is such that its attraction for the moon or for masses on its surface is a maximum, or not; we do not know whether or not the gravita tion constant, as it has been determined, has the value that it would have if $\mathrm{V}$ were really zero on the earth. Some of the smaller masses in our solar system appear to disobey Newton's law.

It is evident that when small masses of matter are suddenly drained of negative corpuscles, we should expect explosive effects to follow. Such a condition is produced when a small metal wire is placed in the positive discharge line, a condenser of large capacity being connected with the terminals of the machine.

The substance of a paper presented to the American Philosophical Society at its annual meeting, April, I9I3, by the present author is presented in illustration of this point. ${ }^{1}$

In I8I5 Singer published in the Philosophical Magazine ${ }^{2}$ an account of experiments made in Holland by De Nelis, and repeated by him, which illustrated what he called the explosive effects of electricity. At that time the one-fluid theory was generally held by those familiar with electrical phenomena. It was, however, their belief that the electrical discharge came from the positive terminal.

Singer made use of a battery of jars having an external tinfoil area of 75 square feet. The positive terminal of this battery

${ }^{1}$ Proc. Am. Phil. Soc., Vol. LII, pp. 283-6.

${ }^{2}$ Phil. Mag., Vol. XLVI, p r6r. 
was separated from a terminal leading to a wire of lead having a diameter of $0.0 \mathrm{I}$ inch. This lead wire was within a small metal cylinder formed by boring a hole into a metal rod. One end of the wire was in contact with the bottom of the bore, the other being attached to a copper wire through which the discharge was sent to the lead wire. This leading-in wire was surrounded by wax, and the lead wire was surrounded by oil. The lead wire was exploded by each discharge. The metal cylinder was stronger than any gun barrel. It, however, was shattered by the explosive effects, the leading-in wire was blown out and the liquid was sometimes thrown to the height of 50 feet when the metal cylinder did not burst.

At the present time it seems evident that, in these experiments, the lead wire was suddenly drained of its negative corpuscles. What may properly be called a rarefaction wave was sent along the wire. When in this condition each atom of lead repels every other atom. The lead becomes explosive. There are heat effects involved also, which assist in the separation of the atoms, but which alone do not seem capable of accounting for the results.

It seemed to the present writer that it might be of interest to determine whether the explosive effects would be the same when the negative discharge was sent through the wire as when the positive terminal was used. In the former case a compression wave is sent through the corpuscular nebula within the wire. The repulsion effects are impressed upon the oil surrounding the wire. In the latter case the nature of the action seems to be essentially different, as has been pointed out above.

These compression and rarefaction waves are somewhat like those which might be impressed upon a column of water within a rubber tube.

The wire was placed within a glass tube as shown in the adjoining figure. The internal diameter of various samples varied between I and $2 \mathrm{~mm}$. The length of the tube was Io $\mathrm{cm}$. The ends of the tube were provided with copper leading-in wires fitting more or less closely the bore of the tube and to which the fine wire was attached, as shown in Fig. 22. The walls of the tube were from I to $2 \mathrm{~mm}$. in thickness. The space within the tube around the wire was completely filled with 
coal-oil, all air being excluded. The ends of the tube and the leading-in wires were sealed with sealing wax, which held theleading wires in place and secured these wires and the glass tubeto supporting blocks of hard rubber.

The source of electricity was an influence machine, provided with a condenser consisting of twenty sheets of glass $66 \mathrm{~cm}$. square, each plate having a tin-foil coating $30 \mathrm{~cm}$. square. These plate condensers were connected in multiple, the tin-foil area being about 20 square feet on each side. A pivotally mounted ground contact could be connected to either terminal of the machine. By means of a similar contact rod either terminal could be connected with one of a set of discharge rods, provided with an adjustable spark-gap between the knobs. The other discharge rod was connected with the water-pipe system of the building by means of two No. 8 copper wires in multiple. The apparatus shown in the figure was in this ground line. The ground for the machine wasin

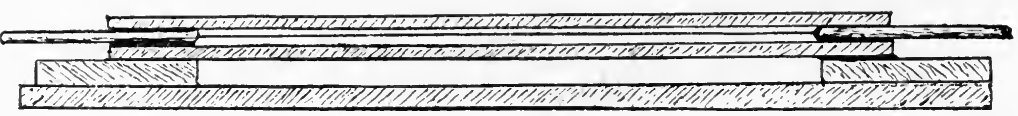

FIG. 22.

the yard outside of the building. The results were the same when the two grounds were thus independent as when they were united.

The wire to be exploded, contained within the glass tube of the figure, was a quarter ampere fuse wire, having a diameter of 0. I I $5 \mathrm{~mm}$. A small copper wire having a diameter of $0.105 \mathrm{~mm}$. was also used with similar results.

A single discharge from either the positive or the negative side of the condenser caused the tube of glass to be shattered into fragments so minute that their impact upon the face of the observer when standing 5 or 6 feet distant, produced no harmful effect. On several occasions, when the discharge came before it was expected, their impact upon the eyes was also harmless. No trace of the metal wire could be found. That no harm could come to the observer became so apparent after a large number of experiments had been made, that no attempt was made to protect either the face or the eyes. The impact upon the eyes could be felt at each explosion thereafter.

The small glass tube shown in the figure was enclosed in a.. 
larger tube having an internal diameter of about half an inch. This tube was also enclosed in a strip of cardboard. In this way the dust into which the inner tube was converted could be collected. It could be recognized as glass only on examination with a pocket lens.

The effect of the explosion on the outer tube, the ends of which were open, was found to be in all cases more marked when the compression or negative discharge was sent through the wire than when the discharge rods and wire were connected with the positive terminal. In some cases the rarefaction wave would produce no apparent effect upon the outer tube, while the negative or compression wave would crack it or shatter it into three or four fragments.

In order to make comparative tests, the apparatus shown in the figure was constructed in pairs, the two tubes being cut from adjoining parts of the same glass tube. This was also done with the larger tubes which were placed between the supporting blocks and surrounded the small tube shown in the figure. In some cases two fuse wires or one fuse wire and one copper wire were placed in parallel within the tube. In this way the explosive effects were somewhat varied. In all cases the greater effects of the compression discharge were so marked that there appears to be no doubt of the result.

In order to compare with these results the heat effects of an ordinary direct current, the wire was, by a switch connection, subjected to the current from a separately excited 250 -volt dynamo. The expansion effects then resulted in forcing the oil out through the sealing wax at the ends of the glass tube. No explosive effects were produced. The same experiment was repeated by switching the lead wire into a ground line attached to a city power plant, the impressed potential being 600 volts. The results were exactly the same as in the previous case, so far as explosive effects were concerned. The wire was fused and partly converted into a fine powder in both cases. The conditions here discussed should be considered in connection with the results shown in Fig. I6.

When the solid conductor is larger in cross-section, the positive terminal of a machine can be in this explosive condition only in a thin film over its surface and under special conditions artificially produced. The fact that molecules of matter when thus suddenly 
drained of negative corpuscles becomes explosive has great significance. It indicates that if this were done for all matter, it would become unstable or explosive. Atoms and planets would repel other atoms and planets. The cohesion of liquids, the tenacity of solids, and the gravitational attraction between cosmical masses, would be lost in universal repulsion, which each atom would have for every other. The behavior of radio-active matter indicates that it may be on the border line.

If the conclusions thus far reached are valid, they lead us to an explanation of the conditions within a brush discharge between positive and negative terminals.

Negative corpuscles issue from within the cathode. If the air around it is in a condition approaching that in a Crookes tube,

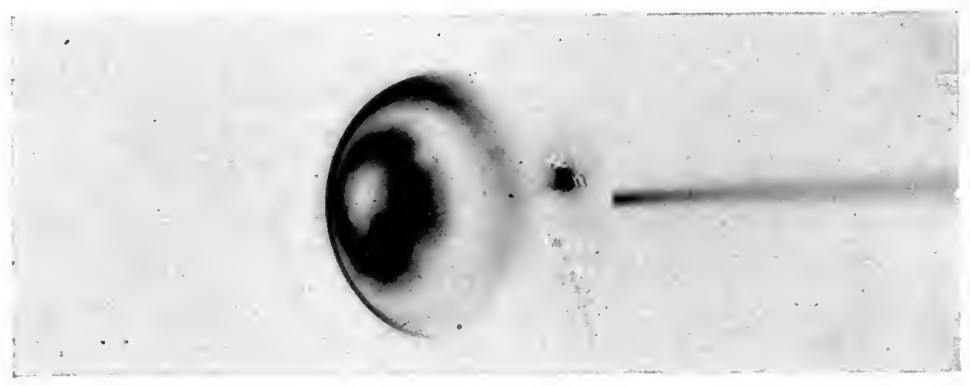

FIG. 23 .

the molecules of air are beaten back from the cathode. The Crookes dark space is thus formed. Collision of these corpuscles with molecules thus beaten away from the cathode, produces the luminous glow, known as the negative glow. If the air pressure within the vacuum tube is increased the Crookes dark space disappears. The negative glow is then in close contact witl $l_{\perp}$ the cathode. The molecules within the negative glow being loaded with an excess of negative corpuscles, are repelled across the Faraday dark space. They repel each other electrically, and there is no appreciable interchange of negative corpuscles between them. This interchange begins when they begin to mingle with molecules within the positive column-the drainage column. If the discharge knobs are moved near together (the condensers being removed) and the conditions represented in Fig. 5 are imposed, 
Faraday dark spaces invade the positive column. The drainage streamers separate from each other. Convection and conduction columns exist side by side. In these columns the air is being urged in opposite directions. These columns jostle each other in a somewhat tumultuous way. The result is that the luminous or positive columns are in the form of concentric cones, separated by similar dark cones. Fig. 23 is a camera photograph of the appearance of the positive knob when the above-described condition exists. The exposure was so timed, that the vibrating luminous columns did not develop. The exposure was followed by a flash-light, a reflection of which is shown upon the polished knob.

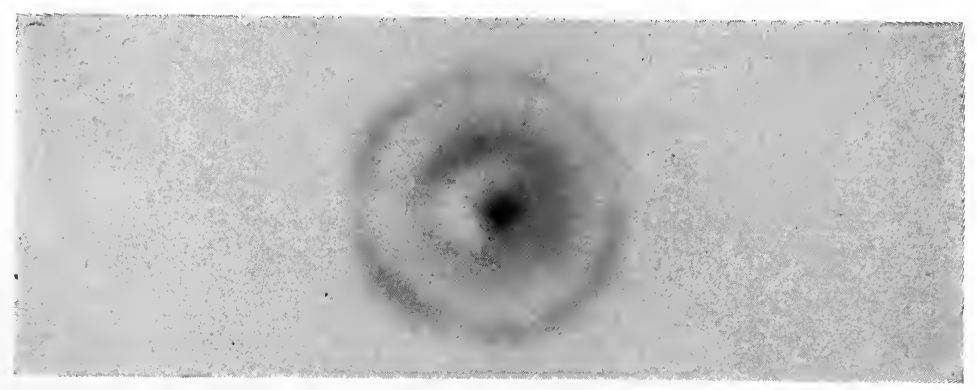

FIG. 24 .

Fig. 24 is a similar reproduction of a negative, of the positive knob taken through a small hole in a copper plate, placed as in Fig. 8. The position and arrangement of these dark and luminous cones, depends upon the length of the small spark-gaps $a$ and $a^{1}$ of Fig. I.

In the Hittorf tube ${ }^{1}$ referred to by J. J. Thomson, ${ }^{2}$ a similar condition exists. Faraday dark spaces and positive columns are joined to the terminals in multiple. The plan of this tube is represented in Fig. 25.

The ends of the electrodes are only I mm. apart. The longer tube joining the bulbs at the bottom of the figure was in spiral form and was $375 \mathrm{~cm}$. in length. Thomson's description of the behavior of the discharge is as follows: "In spite of the enormous difference between the lengths of the paths, the discharge, when

${ }^{1}$ Hittdorf, Wied. Ann., XX, p. 704, I883.

${ }^{2}$ Conduction of Electricity through Gases, 2nd ed., p. 443. 
the pressure was very low, all went round through the spiral, the space between the electrodes remaining quite dark."

The results shown in Figs. 23 and 24 point to a different explanation, as follows:

In the shorter branch of the tube, the dark convection discharge across the Faraday dark space involves a transfer of supercharged gas molecules from cathode to anode. In the longer branch, the electricity is passing by transfer from molecule to molecule, from cathode to anode. The molecules of gas are, however, moving in the opposite direction. The flow of gas in the two branches thus forms a continuous circulation around the circuit of the two branches.

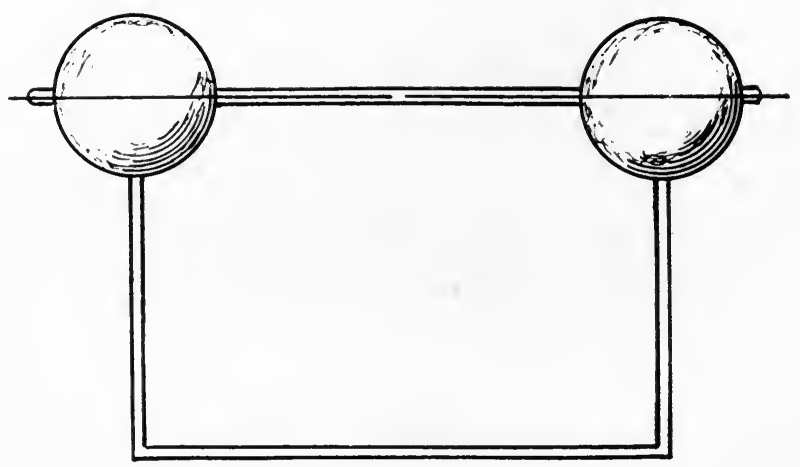

FIG. 25.

A similar condition exists when two knob terminals are brought nearer than what is known as the critical spark length. The dark convection discharge and the luminous or drainage column then exist side by side. The luminous column takes a longer path, having an arc-like form. Thomson interprets this as "showing that it is easier to produce a long spark than a short one." There is then a dark convection discharge between the points of the knobs which are nearest together. This convection discharge crowds the conduction column outward. The air molecules in the dark and the luminous columns are then moving in opposite directions, forming a to-and-fro circulation.

In order to examine in a somewhat different manner the conditions along wire conductors connected with either terminal of the influence machine the method here to be described was employed. 
One terminal of the machine was connected with an earth connection $\left(G_{1}\right.$, Fig. 26) in the yard outside of the building, a sparkgap of $\mathrm{I}$ or $2 \mathrm{~cm}$. being made at the machine terminal. The discharge from the other terminal across a spark-gap of about

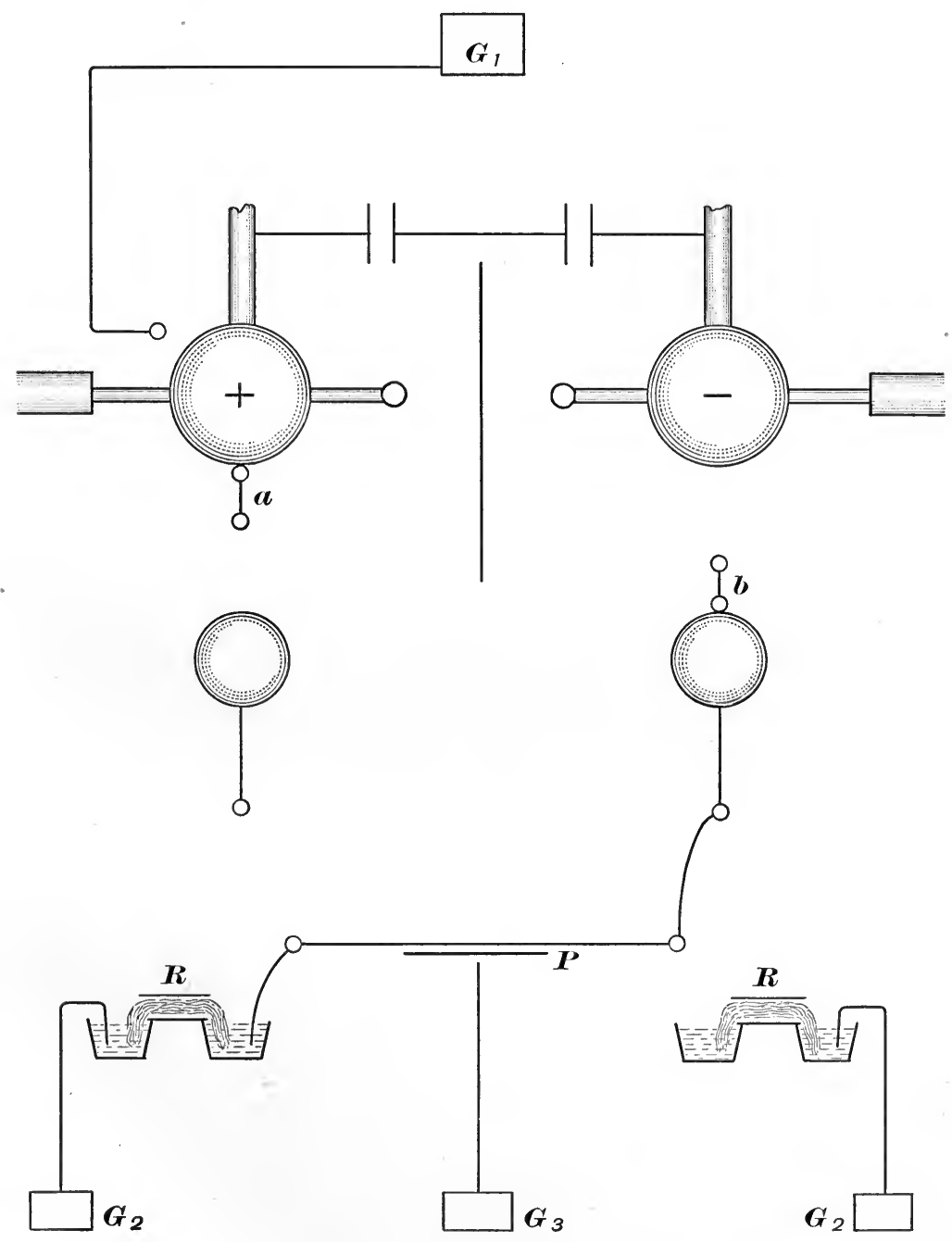

FIG. 26.

$30 \mathrm{~cm}$., was led to an independent ground $\left(\mathrm{G}_{2}\right)$ on an adjoining side of the building. The conductors in both lines were No. 8 copper wire. The line having the long spark discharge through it con- 
tained a high resistance $\mathrm{R}$, near its ground end. This resistance was composed of three or four strips of porous cloth bandage, placed in parallel, their ends being placed in tumblers of salt water. This resistance could be varied by changing the distance between the tumblers, which rested upon glass supports.

A convenient form of resistance is obtained by threading one or more strips of the cloth bandage through a glass tube. The ends of the tube rest upon the brims of tumblers, the cloth conductor dipping into salt water in the tumblers.

Between this resistance and the machine end was inserted a No. 34 copper wire, which passed horizontally across the film of a photographic plate P, Fig. 26, supported at its edges on insulating supports. This wire was held in proper tension by means of brass springs, from which silk cords passed to the wire, and its position with respect to the film of the photographic plate was adjusted by means of hard-rubber supports on either side of the plate having adjusting screws of insulating material. Below the center of the plate a distance of about $\mathrm{I} .5 \mathrm{~cm}$. was the pointed end of a copper wire, which was grounded on the water pipe, $\mathrm{G}_{3}$. The resistance $\mathrm{R}$ was so adjusted that a spark discharge would not pass from the wire above the film around the plate $\mathrm{P}$ to the grounded wire below, but would be on the point of doing so. This adjustment was made for the exposures in the positive and also in the negative line.

Plate I shows a $5 \times 7$ inch photographic plate across which 5 spark discharges from the negative terminal were passed. The fine wire which carried the discharge was in contact with the film. This wire was surrounded by a glow of light, but the resistance between the plate and the ground was not sufficient to force discharges over the film. To have made this resistance greater would have brought about a spark discharge around the plate when the pointed ground conductor was put in position, although it was not in position during this exposure. The effect produced by introducing this ground wire $\mathrm{G}_{3}$ is shown in Plate II. This plate was otherwise exposed exactly as the former plate. The ground wire terminated in a pin-point $1.5 \mathrm{~cm}$. below the center of the plate. The result in Plate II may be explained as follows:

I. By the Two-fluid Hypothesis. - The negative discharge through the wire in contact with the film, is attended by a positive dis- 
charge from the pin-point on the ground wire to the lower face of the plate. This positive discharge is spread over an area coincident with the blackened area which the negative discharge is shown to cover in Plate II. The glass plate on which the photographic film is spread is in a condition like that of the glass wall of a Leyden jar which has been charged from the negative terminal of the machine.

2. BytheOne-fluid Hypothesis. - The negative discharge flowing under compression through the wire above, finds in the grounded wire below a line of leakage. This ground wire greatly increases the potential drop at that point. A negative discharge from the lower face of the glass plate passes to the pin-point and ground wire below. Simultaneously a negative discharge from the upper wire flows over the film, and tends to flow downward to the ionized melocules of glass in the lower face of the glass plate. It constitutes a bound charge.

These discharge effects can be explained by either hypothesis. The photographic plate below and closely around the wire in Plate $I$ is a region of negative glow. Just outside is the Faraday dark space, into which the overcharged molecules of air are repelled. These repelled molecules do not mingle with air in the condition in which it is in the positive column. Luminous effects exist only in the immediate vicinity of the wire, where corpuscles emitted from the wire are loaded upon the molecules of air in contact with it.

Plates III and IV are reproductions of two photographic plates which have been exposed in precisely the same way. The "discharge" through the wire came from the positive terminal of the machine. The spark length was about twice as great as the negative sparks used in producing Paltes I and II.

This adjustment could be made without producing sparks of a disruptive character over the plate when the ground wire with its pin-point terminal was placed below the photographic plate, as was done in Plate IV. In such exposures adjustable spark terminals $a$ and $b$, Fig. 26, were used. They were so placed that the negative discharge passes from a large knob to a small one. In case of a reversal of the electrification of the machine, the adjustable terminals are transferred to the other terminals of the spark-gaps. 


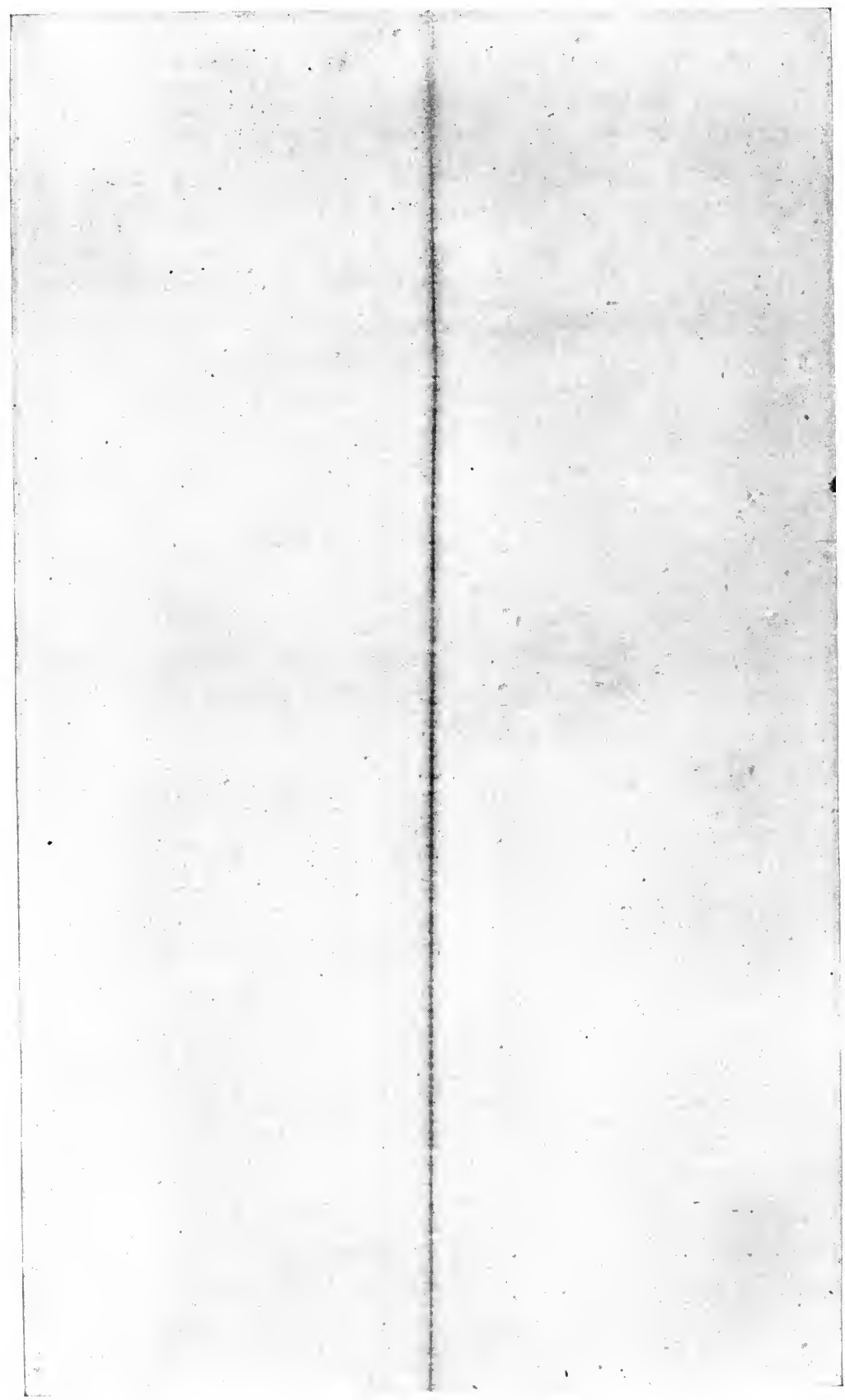

Plate I. - Negative Line. 
The Negative Outflow

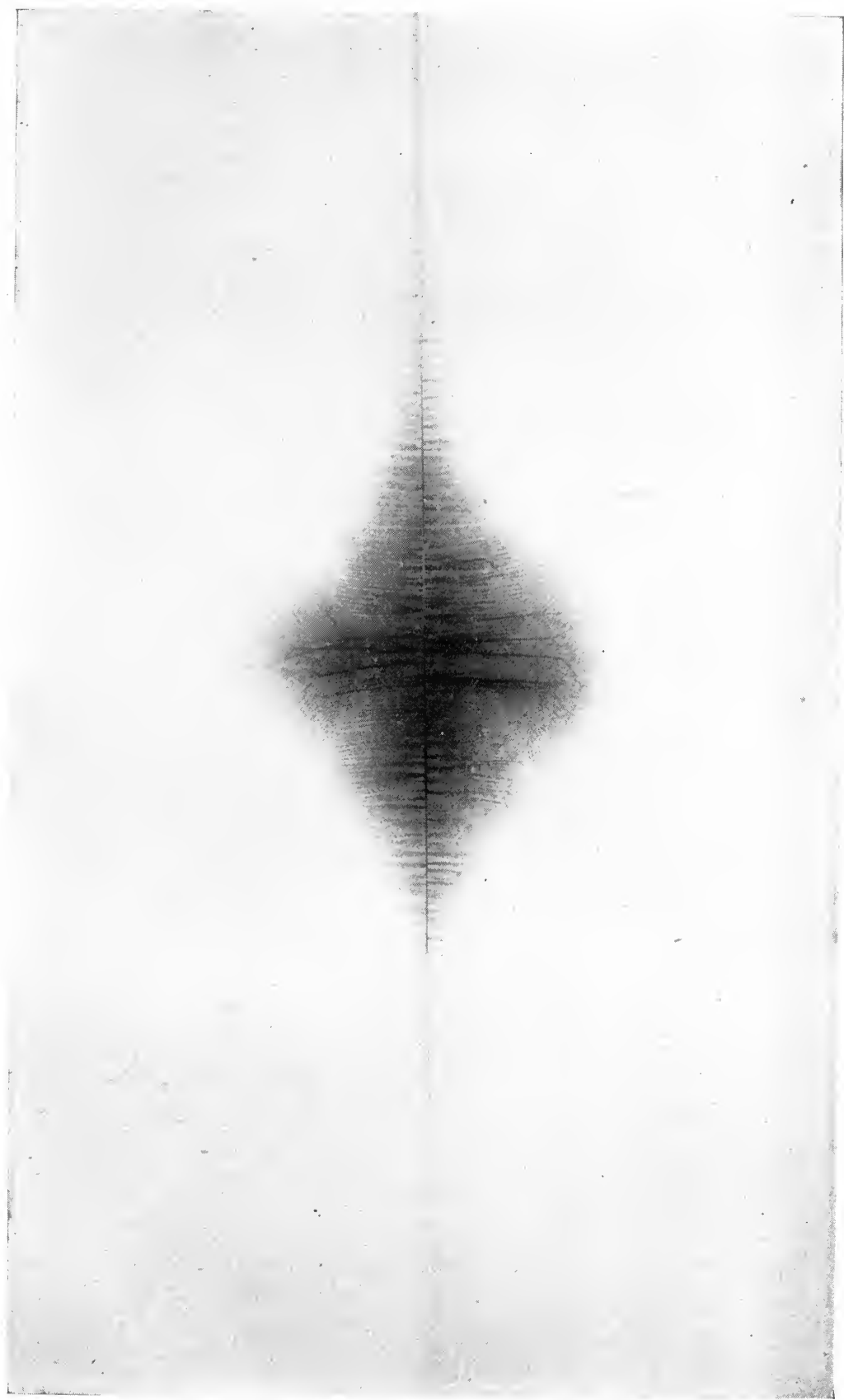

Plate II.-Negative Line. Grounded Point Below. 
The streamers which surround the wires in Plates III and IV are the streamers of the positive column. If they are the result of an outward discharge of positive electricity, the result in Plate IV should be similar to that of Plate II. Negative electricity flowing upward from the grounded pin-point to the back side of the photographic plate should cause a condenser effect. There should be an intensification of the discharge over the film in this region, as in Plate II. The positive outflow there should be intensified.

If these positive streamers are drainage lines, as prior evidence has shown them to be, this inflow over the film to the wire should be diminished over the area lying above that fogged by the negative discharge from the grounded pin-point. This is precisely what occurs.

The fogging in the central part of the plate is wholly due to the discharge from the pin-point. This is shown by the fact that it is not visible after the plate has been developed and before it has been fixed, when the plate is viewed from the film side. It is visible when the film is observed from below. When two plates are used, one having the film in contact with the wire, and the other having the film facing the pin-point, the fogging effect is all upon the lower plate, if the exposure is of the character given in Plate IV. With long-continued exposure or with a larger condenser, the upper film may be slightly fogged through the two glass plates.

The result shown in Plate IV appears to be wholly inconsistent with the two-fluid theory.

Another experiment which strongly favors the one-fluid theory, was described by the author in I900, in a paper entitled, "On Certain Properties of Light-struck Photographic Plates." 1 The phenomenon described has some resemblance to what has been called ball lightning. Figs. 8, 9 and to of that paper show traces on a photographic film, made by a slowly moving point of light. The motion of the point of light was always in the direction of flow of a negative discharge, and came from the negative terminal of an influence machine. A metal disc having a diameter of a centimeter was armed with a pin-point. The point was bent over so that when the disc was placed on the film, the point made

${ }^{1}$ Trans. Acad. of Sc. of St. Louis, Vol. X, No. 6. 


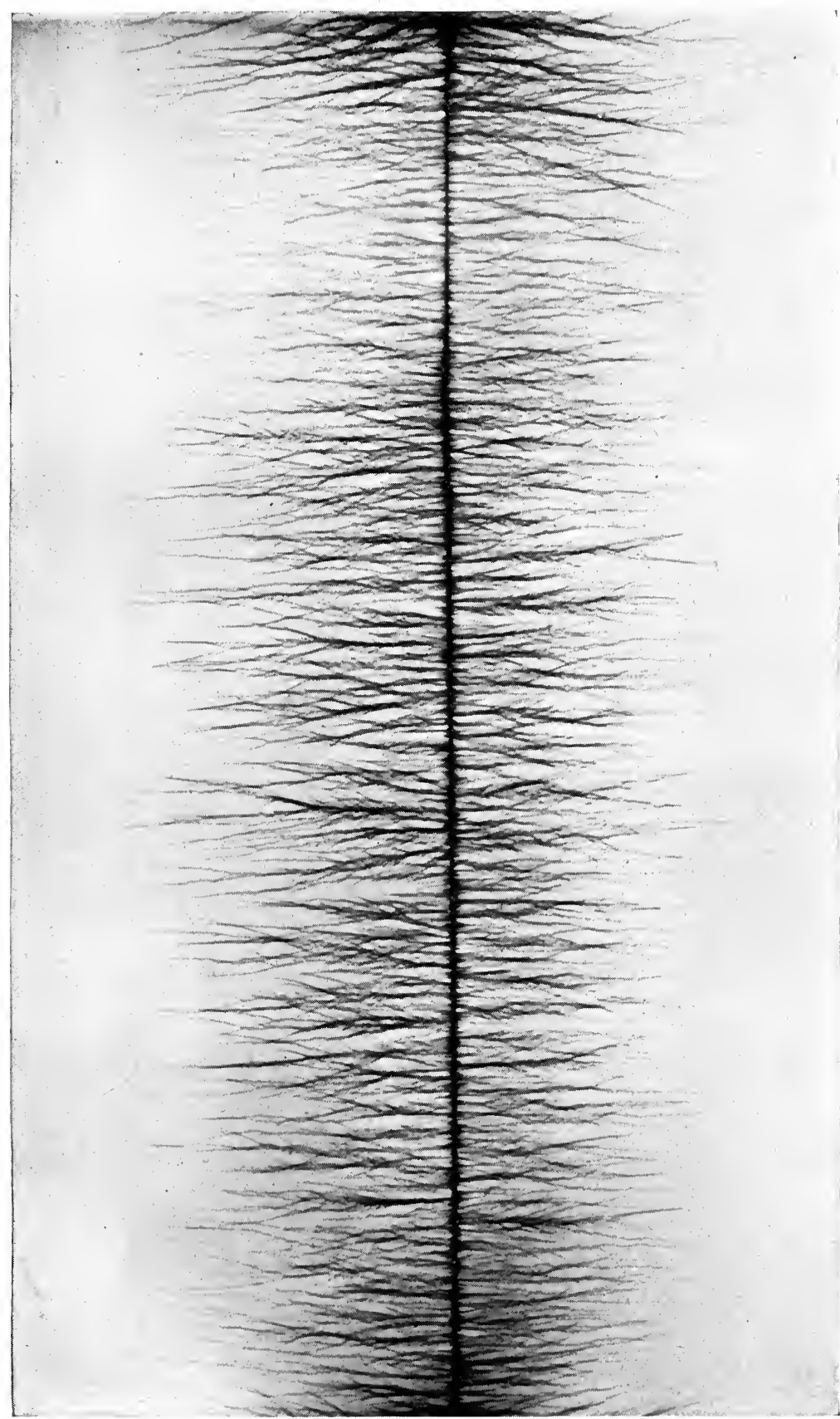

Plate III.-Positive Line. 


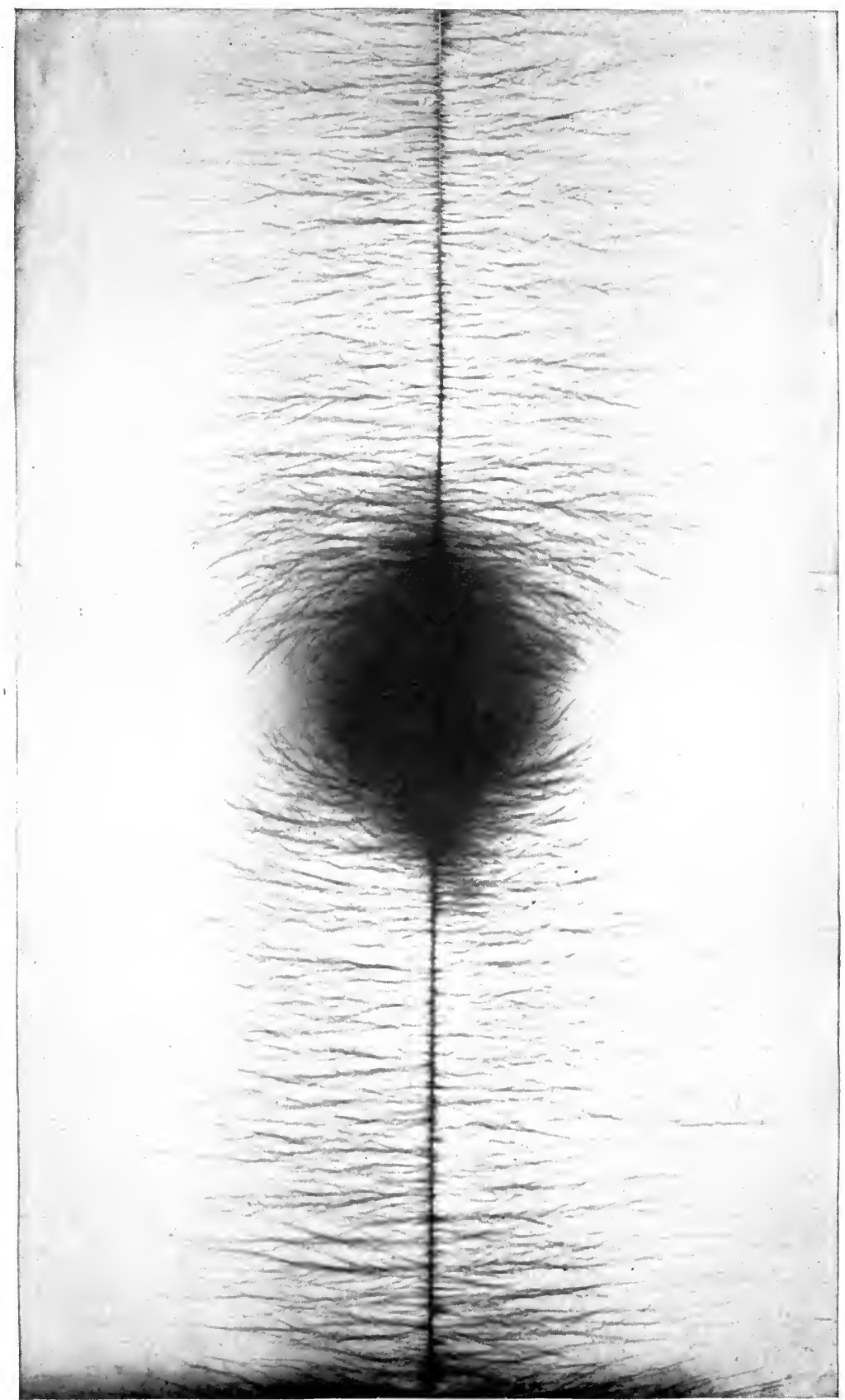

Plate IV.-Positive Line. Grounded Point Below. 
intimate contact with the film. The point rested upon a short pencil mark on the film. 'A slight moistening of the pencil mark is of advantage. The knobs of the machine should be widely separated, and it is of advantage to place a large sheet of glass midway between them, so that no disruptive discharge may occur. The disc is to be in metallic connection with the negative terminal. A point of light emerges from the pin-point on the pencil mark, and moves slowly over the film, curving toward the positive terminal of the machine, and leaving a darkened trail behind. Along this trail an invisible negative flow is taking place, as can be seen by bringing near to it a device which has earned the name of "teazer." This consists of two pins, tied or soldered together at their head ends, the points being in opposite directions. This is mounted at its middle point by means of sealing wax, to a long tube of glass. One of these points when presented to the pin-point on the disc will usually start the ball discharge, if it fails to appear.

It was found to be impossible to obtain these ball discharges from the positive side of the machine. When the teazer was used, these discharges would come from the point on the teazer and would move toward the positive terminal. Plate $\mathrm{V}$ of this present paper shows such discharges. At the top of the figure were placed two discs armed with pins, which were connected to the + and - terminals of the machine. Below were two similar discs opposite to those above mentioned, mounted on the same photographic plate, which was ro $X$ I 2 inches in size. ${ }^{1}$ These discs were in metallic connection with two large gas torches hung on insulated supports in the air outside the building. The torches were fed by means of long rubber tubes, ending in short metal pipes to which the line wires were soldered. Ball discharges came one after the other from the negative terminal, some of which went to the torch terminal opposite, some turning toward the positive terminal of the machine. Ball discharges also appeared from the torch opposite the positive terminal and went to that terminal. The plate was exposed and developed in daylight, the developer being hydrochinone, which was weak in sodium carbonate. Similar results may be obtained by replacing the torches by metal wires, each being armed with about 500 pin-points. The black

${ }^{1}$ Separate plates for the + and - circuits permit them to be more widely separated, and give better results. Smaller plates may then be used. 
lines on the film are shown even when the plate is fixed without being developed. The discharges are not discharges through the air or over the surface of the film. They are within the body of the film itself, and the film shows a distinct depression along the discharge lines.

These effects may be produced between the terminals of the machine, without any ground lines. Similar and much larger ball discharges may be made on a surface of wood by means of a powerful spark-coil operated by a direct current with a Wehnelt interrupter. If an alternating current is used in the primary, ball discharges may be obtained from both terminals simultaneously. They may be led into various paths, but cannot be brought together. 'The tracks are burned into the wood, and are 2 or $3 \mathrm{~mm}$. in breadth.

A Crookes tube may be placed in either of these discharge lines, from the terminals of an influence machine, both lines being carried to independent ground contacts. If placed in the positive line, the cathode terminal of the tube must be turned to the ground.

This ground may be on a torch, or in a many-pointed conductor, or the cathode may be grounded directly on a water pipe. Equally good X-ray pictures may be obtained in the positive or in the negative lines, with equal times of exposure. When placed in the positive line, however, the tube seems to operate in a less positive manner than when operating in the negative line. When this was first done by the author in 1902, the behavior of the tube and discharge line created the suspicion that there was a condition in this line which was in the nature of a rarefaction. Electric discharges from all surrounding objects seemed to be flowing in upon the tube and the positive line. These objects were tipped with brush discharges. The cathode discharge seemed to be somewhat unsteady and was easily disturbed by the movement of near-by objects. Attention was called to this phenomenon and to the "ball-lightning" discharge in a paper before the International Congress of Arts and Science in 1904.

This behavior of the Crookes tube, in connection with the phenomenon which resembles the ball lightning discharge, caused me to make the experimental study of electric discharge the results of which are presented in this volume. 


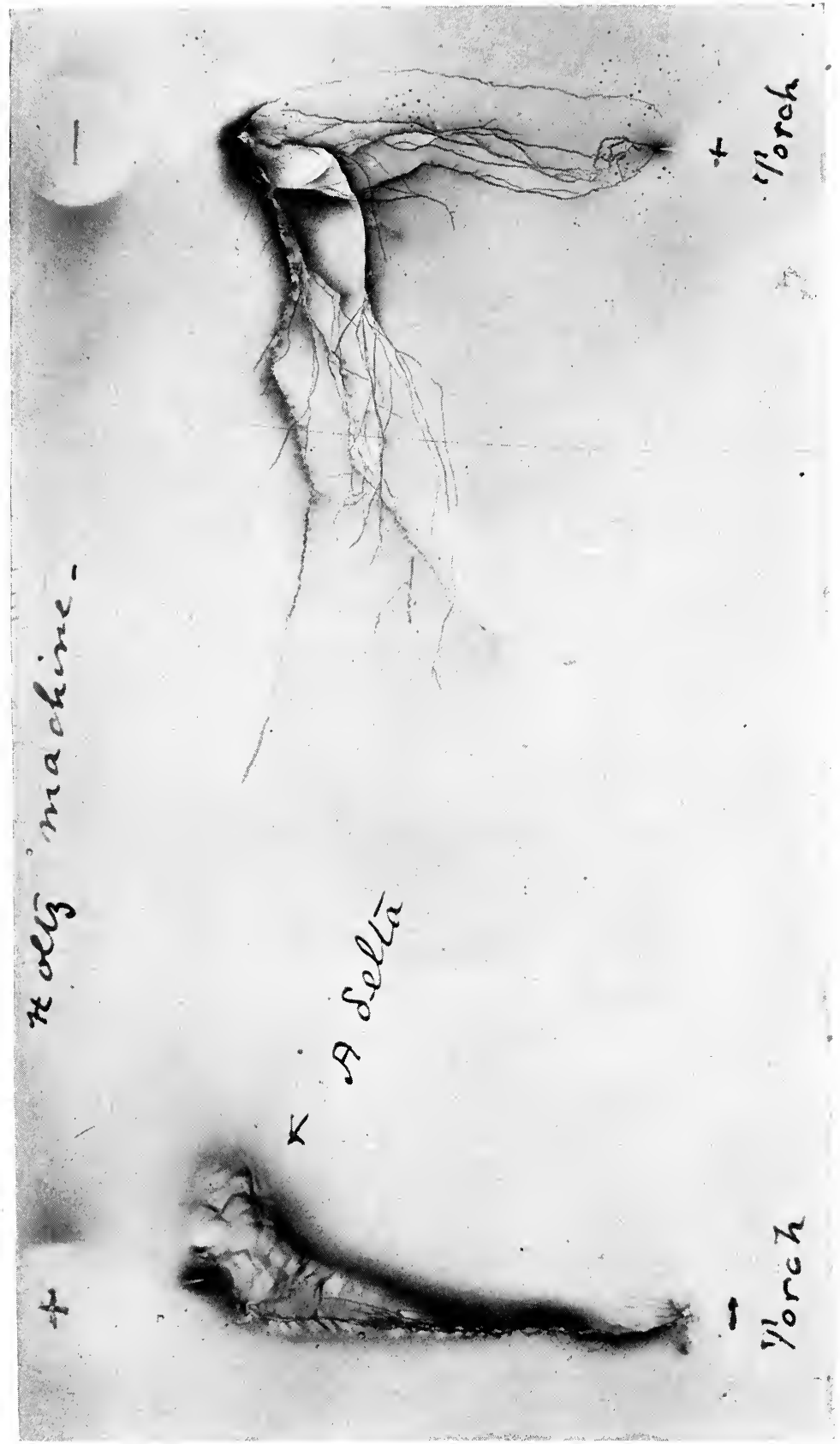

Plate V.-Ball Lightning Discharges. 
We may now give attention to the metal conductor through which a discharge passes.

Rowland's experiment on electrical convection, ${ }^{1}$ made in the laboratory of Helmholtz, showed that a positively charged wire moved longitudinally in either direction, and a negatively charged wire moved in an opposite direction, would produce the same electro-magnetic field. If the two-fluid theory is in accordance with the facts, then, if the external field is impressed upon a metal wire, which is free to move, positive and negative discharges should be urged in opposite directions, and the wire should remain at rest.

On the other hand, assuming the one-fluid theory, the wire itself is a solid aggregation of positive ions. It is a positive column. It should be urged in a direction opposite to that of the negative discharge.

A copper wire $50 \mathrm{~cm}$. in length and having a diameter of 0.23 $\mathrm{mm}$. was placed in a glass tube supported at its middle point in a horizontal position. Tubes of various internal diameters between I and $5 \mathrm{~mm}$. have been used, and all give similar results. The length of the tube is such that the wire protrudes from it at each end, a distance of 5 or $6 \mathrm{~cm}$. The ends were bent downward at right angles to the horizontal part of the wire, in order to eliminate end effects.

Two discharge knobs forming the terminals of rods 2.5 meters in length were placed with their centers over the ends of the glass tube. The rods were supported near the glass tube by silk cords. The other ends rested on the discharge rods of an influence machine driven by an electric motor. It is of advantage that the knobs be placed above the ends of the tube. The protruding ends of the wire are slightly lifted just before the sparks occur. This prevents bending of the wire around the edge of the glass at the end of the tube, from interfering with the longitudinal creeping of the wire.

The discharge gaps at the ends of the glass tube were made equal. The discharge knobs had equal diameter. The gaps usually had a length of 4 or $5 \mathrm{~cm}$. each, so that discharges could be freely produced, at intervals varying from half a second to three seconds.

The experiment was varied by suspending the wire on three or

${ }^{1} \mathrm{Am}$. Jrl. of Sc. [3], XV, $30-38,{ }_{1} 878$. Physical Papers of Rowland, p. I 28. 
four silk fibers. One was attached at the middle of the wire, the others a couple of inches inside of the spark terminals. These terminals were in the form of rings which closely encircled the wire. These rings were at the ends of brass rods lying in the same horizontal plane as the wire, and leading to the machine terminals about Io feet distant.

The air in the room must be very quiet, in order to prevent its effect upon the suspending fibers of silk. Such circulation as exists in a room heated by warm air interferes with the result. If the wire is placed in a tube as in Fig. 27 referred to above, the tube may be divided in half, and a pointer consisting of a fine fiber of glass, or a silk fiber, may be attached to the wire between the
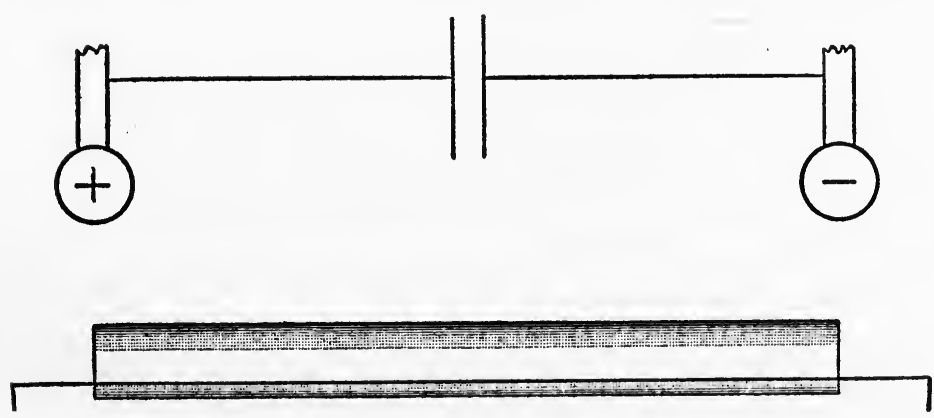

Fig. 27.-Apparatus Showing the Gradual Creeping of a Wire in a Direction Opposite to the Corpuscular Discharge.

tubes. This serves as a mark upon which the telescope may be set, for observing the displacement. The support for the glass tubes must of course be provided with leveling screws.

The spark discharges used were from two large Leyden jars. Larger condensers may disturb the result by causing a wire of this size to buckle.

It was found that the wire did not appreciably move when any spark discharge passed through it. When lying in the glass tube, after six or eight discharges had been made, it could be seen that the wire had moved.

When the direction of the discharge was reversed, and leveling adjustments had been made, the wire crept in the opposite direction. This operation has been continued for hours. In one case in which 3500 discharges were made, the wire moved over a distance of $1.2 \mathrm{~cm}$. A plate-glass condenser was used, the area 
of the brass sheet on each side being about Iooo sq. $\mathrm{cm}$. When the wire was hung on silk fibers, summation effects were obtained, by means of brushes, each composed of 4 or 5 hairs from the tail of a horse. They were mounted in a vertical position on blocks of rubber resting on a plate of glass. The brushes were moved into contact with the sides of the wire. The contact was just sufficient to prevent the wire from moving backward after the faint displacement due to each discharge was obtained. On many occasions the wire was apparently prevented from moving, by some frictional contact, or irregularity of surface, which could not be detected. A slight displacement would then remedy the trouble. In a few cases where the discharge had been continued for hours, the wire appeared to become less sensitive. It could not be made to move. When left in this position for a day or two, it at once responded by moving as if it were a positive column. These results suggest that there may be fatigue effects involved. Such results were obtained by accident in a sheet of hard rubber. Five fibers of red glass had been mounted upon a frame of hard rubber. The fibers were laid upon the film of a photographic plate and placed in a holder of hard rubber. This holder was placed upon a sheet of glass below which was a metal sheet serving as the positive plate of a condenser. The other metal plate was placed above the holder. It was supported by blocks of hard rubber, so that it was lifted slightly above the hard-rubber plate-holder. One hundred spark discharges were sent across the machine terminals to which the condenser was attached. The spark length was about $30 \mathrm{~cm}$. Shadow images of the glass fibers were produced on the photographic film, such as are produced by Röntgen rays.

In Fig. 28 such shadow images were produced, but in this instance the glass fibers had been left out by mistake. The fibers had been on another photographic film, which had been previously exposed in the same holder.

These shadow images are therefore due to glass fibers which had never been in contact with this photographic film. Their prior presence in the same holder on another film, had resulted in producing after-effects in the hard-rubber cover. This figure also shows fainter images of the glass fibers in the position they had been in during a still earlier exposure, the hard rubber frame on which the fibers were mounted having been reversed in position. 
Fig. 28 is a reproduction of the original plate. A shadow of the hard-rubber frame on which the fibers were mounted is also shown around the edges of the figure.

When the holder was opened and it was discovered that it contained nothing which could produce a shadow picture, the first impulse was to deposit it in a scrap-heap in which thousands of other plates had been placed, by reason of their non-instructive character. The idea of after-effects suddenly presented itself, and the accident was made useful. ${ }^{1}$

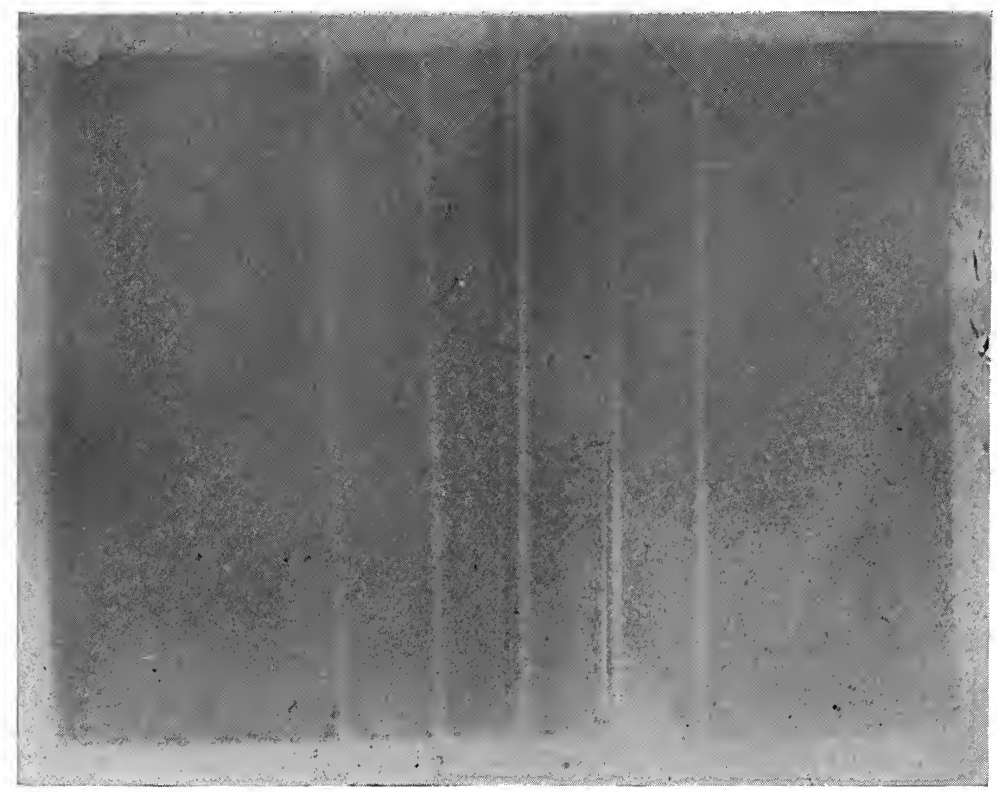

FIG. 28.

Another question which has received attention in the past is the velocity with which the electric fluid moves in the conducting wire. On this subject Maxwell makes this statement: ${ }^{2}$

"As to the velocity of the current, we have shown that we know nothing about it, it may be the tenth of an inch in an hour, or a hundred thousand miles in a second. So far are we from

${ }^{1}$ This result led to a report that in taking a photograph of the interior of a room, the photograph of a man had been obtained who was not in the room at the time when the photograph was taken, but who had been there on a former occasion.

${ }^{2}$ Electricity and Magnetism, II, p. I97, I88I. 
knowing its absolute value in any case, that we do not even know whether what we call the positive direction is the actual direction of the motion or the reverse."

In 1895 the present writer made a suggestion, which is of interest in this connection, although it does not give any grounds for a decision of the question which Maxwell suggests. ${ }^{1}$ It does suggest that the velocity of flow is greater than an inch in an hour.

Imagine two conducting spheres having radii equal to that of the earth, or $6.37 \times 10^{8} \mathrm{~cm}$. Let them be charged to potentials +25 and -25 volts. Connect them with a wire containing in circuit a 5o-volt I-ampere lamp, the resistance of the wire conductor being neglected. In order to maintain the potential difference on the two spheres constant; and thus maintain normal candle power in the lamp while all of this store of electricity is being used, the two spheres must be forced to collapse to zero radius at a uniform rate of motion.

$$
\text { Since } \begin{aligned}
\frac{\mathrm{Q}}{r} & =V \text { we have } \\
d \mathrm{Q} & =V d r=i d t
\end{aligned}
$$

or

$$
t=\frac{V}{i} r=\frac{50}{300} \frac{6.37 \times 10^{8}}{3 \times 10^{9}}=0.0354
$$

The time during which the operation of the lamp could be maintained by this amount of electricity is therefore 0.035 second. We must therefore think of this operation as being continuously repeated 28 times a second in order to maintain a 50-watt lamp in normal operation. The velocity with which the radii must shorten from $6.37 \times 10^{8} \mathrm{~cm}$. (4000 miles) to zero during each stroke of the piston of this electrical pumping service, is $1.8 \times 10^{10}$ $\mathrm{cm}$. per second, or about II3,000 miles per second. This is more than half the velocity of light.

A discussion of a similar character was made in I9II, which seems to be somewhat more instructive. ${ }^{2}$

Suppose a copper wire of radius $r$ and length $\mathrm{L}$ to be surrounded

1 Nipher, Electricity and Magnetism, p. 390, § 222.

${ }^{2}$ Nipher, Trans. Acad. of Sc. of.St. Louis, Vol. XX, p. I2. 
by a co-axial surface of radius $r^{\prime}$. The two surfaces form a condenser of capacity

$$
\mathrm{C}=\frac{\mathrm{L}}{2 \log _{\epsilon} \rho}
$$

where $\rho=\frac{r^{\prime}}{r}$.

Ground the outer shell, thus keeping its potential zero. Charge the wire core to a potential V. Connect one end of this core to a ground of infinite capacity through a resistance

$$
\mathrm{R}=\frac{l}{k s}
$$

Move the condenser toward the resistance $R$ with a velocity $v$, and assume that the condenser-wire collapses longitudinally at the point where it makes contact with the resistance $R$. The velocity $v$ is to be so adjusted that the potential $V$ remains constant. The current delivered to the wire of resistance $R$ is then

$$
i=\frac{d \mathrm{Q}}{d t}=\mathrm{V} \frac{d \mathrm{C}}{d t}=\frac{\mathrm{V}}{2 \log _{\epsilon} \rho} \frac{d \mathrm{~L}}{d t}
$$

The velocity with which the wire must move is

$$
v=\frac{d \mathrm{~L}}{d t}=2 \log _{\epsilon} \rho \frac{i}{\mathrm{~V}}=2 \log _{\epsilon} \rho \frac{\mathrm{I}}{\mathrm{R}}
$$

From this equation it would appear that if the capacity of the condenser per unit length is infinite or $\rho=\mathrm{I}$, the velocity $v$ will be zero if $\mathrm{R}>0$.

On the other hand if the velocity $v$ were made equal to that of light, $\mathrm{R}$ being in electrostatic units

$$
\log _{\epsilon} \rho=\frac{\mathrm{I}}{2} 3 \times \mathrm{IO}^{10} \mathrm{R}
$$

If $\mathrm{R}$ is measured in ohms

$$
\begin{aligned}
\log _{10 \rho} & =\frac{0.434294 \times 3 \times 10^{10} \times 10^{9}}{2 \times 9 \times 10^{20}} \mathrm{R} \\
& =0.007235 \mathrm{R}
\end{aligned}
$$

The values of $\rho$ for various values $\mathrm{R}$ are given in Table I. 


\begin{tabular}{|c|c|}
\hline R ohms & $\rho$ \\
\hline $0 . \mathrm{I}$ & 1.0016 \\
\hline 1.0 & 1.01 68 \\
\hline 10.0 & I. I8I \\
\hline 100.0 & 5.290 \\
\hline
\end{tabular}

\begin{tabular}{r|c}
\multicolumn{2}{c}{ TABLE II } \\
$\rho=1.0016$ \\
\hline R ohms & $v$ \\
\hline & \\
\hline 0.1 & $3.00 \times 10^{10}$ \\
1.0 & $3.00 \times 10^{9}$ \\
I0.0 & $3.00 \times 10^{8}$ \\
100.0 & $3.00 \times 10^{7}$ \\
\end{tabular}

If the value of $\rho$ be made r.oor $64+$ as in the case given in the first line of Table I, the value of $v$ for the various values of $\mathrm{R}$ are given in Table II. The current delivered will of course depend on the value $\mathrm{V}$.

The quantity of electricity per unit length of the condenser core is

$$
\frac{d \mathrm{Q}}{d \mathrm{~L}}=\frac{\mathrm{V}}{2 \log _{\epsilon} \rho}=\frac{\mathrm{V}}{\mathrm{R} v}=\frac{i}{v}
$$

The current in terms of the velocity $v$ is therefore

$$
i=v \frac{d \mathrm{Q}}{d \mathrm{~L}}
$$

If we now consider the conditions within the wire of resistance $\mathrm{R}$, to which this current is being delivered, $v^{\prime}$ being the velocity with which the fluid flows in the wire, we shall have an equation similar to the last, or

$$
i=v^{\prime} \frac{d \mathrm{Q}}{d l}=\frac{\mathrm{V}}{l} k s
$$

On the condenser core, the convection current is carried on a thin film of its surface. In the wire of resistance $R$, the same current is distributed uniformly over a cross-section $s$. The relation between the conduction resistance $R$ and what may be called the convection resistance is

$$
\frac{2 \log _{\epsilon} \rho}{v}=\frac{l}{k s}
$$

When the values of $v$ and $\rho$ satisfy this equation the potential of the condenser core will be constant and the current through $\mathrm{R}$ 
will therefore be constant. The velocities $v$ and $v^{\prime}$ will then be such as to satisfy the condition.

$$
v \frac{d \mathrm{Q}}{d \mathrm{~L}}=v^{\prime} \frac{d \mathrm{Q}}{d l}
$$

If the wire of resistance $\mathrm{R}$ were now to be replaced by one having a length $2 l$ and a section $2 s$, the current would remain unchanged. The potential or electrical pressure at the end which joins to the condenser core would remain unchanged. The current per unit cross-section and the drop in potential per unit length will be half as great as before. If we are to consider the amount of moving electric fluid contained in I c.c. of the wire to be the same as before, then $v^{\prime}$ will have been reduced to half its former value, and $\frac{d Q}{d l}$ will have been doubled. It would then require four times the time for a given element of the fluid to traverse the resistance $\mathrm{R}$, that was needed for the wire of half the length. This involves an abrupt change in the velocity of the corpuscles, at the point where the cross-section $s$ changes, in any circuit. As an illustration assume that a tube of cross-section $\mathrm{S}$ contains a column of sand of length $l$, and in series with it contains a column of gravel of length $l_{2}$. The lengths are such that the two columns have equal resistance to the flow of a fluid through them. We may assume that the effective cross-sections of these columns are $\mu_{1} \mathrm{~S}$ and $\mu_{2} \mathrm{~S}$. The current flowing through the two columns is

$$
i=v_{1} \mu_{1} \mathrm{~S}=v_{2} \mu_{2} \mathrm{~S}
$$

where $v_{1}$ and $v_{2}$ represent the velocity of flow. The distances over which the flow will pass within these columns, during a time $t$ will be

$$
\begin{aligned}
& d_{1}=v_{1} t \\
& d_{2}=v_{2} t
\end{aligned}
$$

The resistance of these two columns, neglecting frictional effects would be

$$
r=\frac{l_{1}}{\mu_{1} \mathrm{~S}}=\frac{l_{2}}{\mu_{2} \mathrm{~S}}
$$

Let the time required for the liquid to pass from end to end of the two tubes be $t_{1}$ and $t_{2}$ then 


$$
\begin{aligned}
& l_{1}=v_{1} t_{1} \\
& l_{2}=v_{2} t_{2}
\end{aligned}
$$

Hence

$$
\frac{v_{1}}{v_{2}}=\frac{d_{1}}{d_{2}}=\frac{l_{2}}{l_{1}}=\frac{\mu_{2}}{\mu_{1}}
$$

If these columns of sand and gravel were in multiple, they having pressures in common at their extremities, as in a divided circuit, equal quantities would enter and equal quantities would leave during the same time-interval, the inflow and outflow being equal. Let the two columns be of the same material. The tubes containing them will then have sections $S_{1}$ and $S_{2}$. The length $l_{1}$ and $l_{2}$ are to be such that they have equal resistance to flow. Then in the equation for $i_{1}, \mu_{1}=\mu_{2}$. In the ratios which follow, $\mathrm{S}_{2} / \mathrm{S}_{1}$ would replace $\mu_{2} / \mu_{1}$.

The electrical conductivity of gold is about five times that of platinum. Assume that $\mu_{2} / \mu_{1}=5$. Then $v_{1}=5 v_{2}$. This would mean that the velocity of flow in platinum is five times the velocity in gold under the assumed conditions. The time required for the flow through the wire of gold would be

$$
t_{2}=\frac{l_{2}}{l_{1}} \frac{v_{1}}{v_{2}} t_{1}=\left(\frac{\mu_{2}}{\mu_{1}}\right)^{2} t_{1}=25 t_{1}
$$

The velocity of flow of the fluid would in all cases increase directly as the quantity per second flowing through any section of the conductor.

In the equation

$$
v \mathrm{R}=2 \log _{\epsilon} \rho
$$

if $\rho$ be given the value assumed in Table II, and the wire to which the current is to be delivered have a resistance O.I ohm the convection velocity of the condenser core must be that of light in order to maintain a constant current.

The capacity per unit length of the condenser is independent of its radial dimensions. If the inner core has a radius of $100 \mathrm{~cm}$., that of the surrounding shell must be I00.16 $\mathrm{cm}$.

The distance between the two surfaces of the condenser would be $1.6 \mathrm{~mm}$. The copper wire having a resistance of o. I ohm may be a No. 26 wire B. W. G. having a radius of $0.23 \mathrm{~mm}$. and a length of $95.6 \mathrm{~cm}$. Under these conditions represented in the 
first line of Table II, the potential of the inner core of the condenser would remain constant, whatever that potential might be. The condenser would be delivering ro coulombs per second to the wire, if the potential of the condenser core were I volt, The current would be io amperes.

Under these conditions it seems difficult to believe that the velocity of corpuscular flow within this wire could be as small as $1^{\frac{1}{0}}$ inch per hour.

We must assume that when negative corpuscles issue from the cathode of the Crookes tube they are capable of imparting kinetic energy to masses of matter. When converged to a focus upon a sheet of platinum, they are capable of producing a marked rise of temperature. They produce similar effects when they collide with the positive carbon of an arc light. When in the circuit of a dynamo, they are forced out of atoms which attract them, and they enter adjoining atoms which also attract them. In doing this they produce atomic vibrations which are apparently comparable with those which can be produced by beating the conducting wire with a sledge hammer. When a change in velocity takes place, as a corpuscular flow crosses the boundary between wires composed of different metals, this change results in a change in temperature. The specific heat of the metal is one factor which determines the change in temperature.

When such a union in a closed circuit is heated, one of these metals delivers negative corpuscles to the other. Similar results are produced when unlike substances are placed in contact, and rubbed together.

The striæ in the positive column of the Geissler tube are explained as electrically produced air waves, similar to those in an organ pipe. The adjoining halves of a wave are Faraday dark spaces, and conduction columns. In these half-waves, the molecules of gas are moving in opposite directions. This involves conditions of maximum and minimum pressure. These changes in pressure involve a change in the conditions of conduction, and result in a constant variation in the position of the striæ.

Vibrations in the spark-gaps $a, a^{\prime}$ of Fig. I, impress waves in the corpuscular nebula within the conductors. Where the electric fluid is under compression, the outer surface of the wire is supercharged. Between these compression points the surface of the 
wire has a deficiency of the negative fluid. A drainage inflow from the air will here occur, such as exists in the positive "discharge." This is also sometimes known as a coronal effect.

It is also evident that in adjoining semi-waves the conditions exist which tend to cause a longitudinal collapse of the wire. The wire tends to become shorter. When large discharges are made through a wire of small cross-section, it buckles into waves. This phenomenon was apparently first discovered by Edmund Becquerel, in 1839. (Pogg. Ann. Bd. 48, S. 546.)

After the manuscript of this volume was sent to the publisher, an attempt was made to apply a reversal of the Rowland effect to a column of distilled water.

Two beakers each having a capacity of $\mathrm{I} / 2$ liter were partly filled with distilled water, which had been freshly boiled. The water in the two vessels was connected by means of a glass tube forming a siphon. Platinum terminals connected with long rods leading to the knobs of the influence machine were inserted in the two vessels.

It was found that when the machine was in action, the water was urged from the beaker at the positive terminal, into the other beaker A difference in level of about $3.8 \mathrm{~mm}$. was produced. There were small spark gaps at the machine. There were no condensers attached.

The siphon above described was replaced by one formed of a capillary tube, having an internal diameter of about $0.2 \mathrm{~m} . \mathrm{m}$. other conditions being unchanged. The same results were obtained. The movement of the water in the siphon was now made apparent. The water column was broken into segments. Bubbles of vapor formed in it. They moved toward the negative end of the tube. In order to maintain this flow the water level in the beaker at the positive end of the siphon was raised 2 or $3 \mathrm{~cm}$. above that in the other vessel. It soon became evident that water was being decomposed within the bubbles of vapor. The gases discharged from the tube were collected. The mixture was explosive. The two platinum wires were enclosed by tubes of glass filled with water, the wires entering at the tops of the tubes. In this way the hydrogen and oxygen liberated at the electrodes was also collected. It was found that the amount of water decomposed in the capil- 
lary tube within the bubbles of vapor, was vastly greater than that decomposed at the electrodes during the same time interval.

In one case during to hours of operation $9.5 \mathrm{cu} . \mathrm{cm}$. of explosive gas was discharged from the capillary tube, while the volume of oxygen and hydrogen collected at the electrodes was $0.18 \mathrm{cu} . \mathrm{cm}$. In the same circuit, the same discharge decomposed more than fifty times as much water by impact within the vapor, as was decomposed by it within the liquid by electrolysis.

On one occasion, before accurate means for the measurement of the volumes had been secured, it was estimated that about 800 times as much water was decomposed in the capillary tube as at the electrodes. For a machine of given output, the cross-section

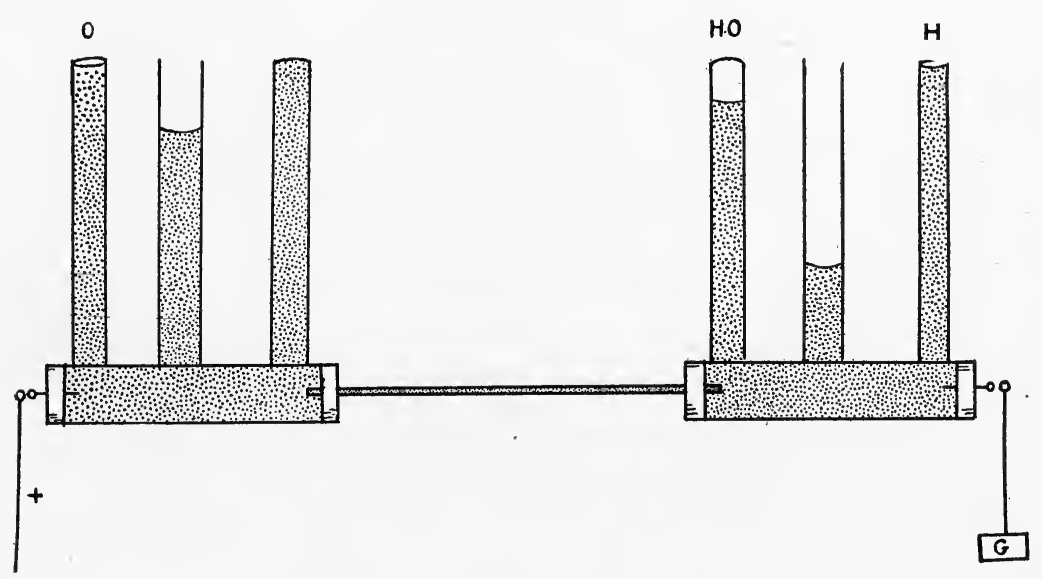

Fig. 29.-Water Decomposed When in the Form of Vapor.

of the tube is an important element in the result. Unless bubbles of vapor form in the tube, no water will be decomposed in it.

It was also found that the siphon was urged in the same direction as was the water column. It would slide upon the brims of the beakers over a distance of 2 or $3 \mathrm{~cm}$. in a fracton of a second. It was necessary to hold it in position.

The beakers were replaced by glass tubes, which were connected by means of the capillary tube, the electrodes entering at the outer ends as shown in Fig. 29. The large tubes were closed by means of four rubber stoppers, which held the electrodes and the capillary tube in place.

Similar results were thus obtained. The siphon arrangement 
has been found to be the more satisfactory. Complications arise from the breaking-down of the rubber stoppers, and from bending stresses in the capillary tube forming part of the service shown in Fig. 29.

There are indications that evaporation from the surfaces of the water in the two beakers is increased by the electrification. The surface film of water in the positive beaker is in a slowly explosive condition. The air around it is in a condition approaching saturation. A cloud of tobacco smoke around it causes a marked deposit of water upon the vessel and the capillary tube. It flows along the horizontal part of the tube when the negative terminal of the machine is grounded. It falls in drops between the two beakers and flows down the wall of the beaker at the negative or grounded end. The distance between the beakers was about $10 \mathrm{~cm}$.

The siphon was removed, and the beakers were replaced by earthenware plates, and an attempt was made to examine the temperature of the water during evaporation. Two thermometers were dipped into the water. The column of mercury in the thermometer placed in the water at the positive terminal was parted at the bulb, and the entire column was driven to the top of the tube, A luminous column was visible in the vacant space thus formed within the tube. Nothing of this kind happened to the other thermometer. The evaporation in both plates is greater than that which takes place during the same time from plates not connected with the machine. The water which is connected with the positive terminal evaporates more rapidly than that in the plate connected with the negative terminal. Of course neither terminal of the machine is to be grounded in this case. This work will receive attention during the coming year. The statements here made are apparently based on conclusive evidence, but the subjects discussed in this after-note require additional investigation. 


\section{Causes of Local Magnetic Storms}

The work of Ampère nearly a century ago, taken in connection with the fact that fragments of a steel magnet are also magnets, was sufficient grounds for the theory that the molecules of magnetic matter may contain closed electrical currents. The discovery of the electron gave additional weight to the older suggestion. With a view of obtaining direct evidence of this condition within a steel magnet, the writer began a series of experiments which have led to interesting results, but which leave the original question unanswered.

It appeared possible that the magnetic force of a steel magnet might be diminished by draining negative electrons from it. This was done by connecting it with the positive terminal of an influence machine.

The magnet to be tested was $30 \mathrm{~cm}$. in length and about 2.5 $\mathrm{cm}$. in diameter. It was composed of a thin film of steel $0.2 \mathrm{~mm}$. in thickness. It was formed of a single layer of steel wire wound longitudinally on a piece of rubber hose, rendered rigid by means of a core of wood. The winding was in the form given the copper windings of a drum armature. The wire was held in place by silk cord, and the steel wire crossing the ends of the hose was removed. The wire was then magnetized.

This wire magnet was used as a deflecting magnet, being placed at right angles to a needle suspended on a silk fiber. The needle wás wholly enclosed in a metal shield. A mirror attached to the suspension was observed through a glass window covered with copper wire gauze. A telescope and scale was used in observing deflections, I $\mathrm{mm}$. having an angular value of $3^{\prime} \cdot 4$. The deflecting effect of the wire magnet was balanced by a large bar magnet placed on the opposite side of the needle. The needle was rendered sensitive to changes in the turning moment of the wire magnet, by partially compensating the effect of the earth's field by means of bar magnets on either side of the needle. The time of a complete vibration in the earth's field within the building 
was the same, when all magnets were removed as when the opposing deflection magnets were in place, namely, 8.94 seconds. The compensating magnets increased the vibration period to 20 seconds.

It was found when either terminal of the influence machine in an adjoining room was connected with the insulated wire magnet, the other terminal being grounded, that the deflecting effect of this magnet was increased. The angle of deviation could not be determined with any precision, on account of fluctuations in the needle, but it amounted to about I $5_{5}$ minutes of arc. In some of the earlier experiments the reverse result was obtained. It was then concluded that the attraction between magnets, like that between masses of matter depends upon their electrical potential. This question is, however, still an open one. It was found when the air around the magnet is rendered as quiet as possible, and when no disruptive effects are permitted along the conductor, that the magnet becomes apparently stronger. It was also found that disturbances of the air around the magnet appeared to diminish its deflection effect. It was found when the charged magnet was covered with tin-foil, that the defection due to electrification was apparently unchanged. It was found when the air around the magnet was disturbed by the movement of an assistant, or by means of a palm-leaf fan, that its deflecting effect due to electrification was diminished. When the fan was operated during alternate semi-vibrations of the needle, the oscillations of the needle could be gradually increased in amplitude to 5 or $6^{\circ}$ of arc.

All of this evidence indicates conclusively, that the apparent increase in the strength of the deflecting magnet when in contact with the terminal of the machine, is due to an increase in the permeability of the air around the magnet.

The "charged" molecules of air appear to behave like iron filings, in that they set in the field of the deflecting magnet with the planes of the electrical whirls at right angles to the lines of force. It was found that a solid steel magnet gives similar results.

A bar magnet thus used as a deflecting magnet, over which a sheet of glass is placed, extending to the shield around the needle, gives most interesting results when the plate is sprinkled with iron filings. An increase in the deflecting effect of the magnet is thus produced. 
The increase in permeability due to tapping the plate is plainly evident. When the filings are gathered in a heap at the equator of the magnet, its deflecting effect is greatly diminished. If at any point in the field of this magnet, the iron filings are disturbed by means of a brush, the magnetic field will be disturbed throughout. If the iron filings were free to move, they would respond to the disturbance. The suspended needle does respond.

When the magnet is mounted on a block resting upon the glass plate and a mass of iron filings is applied to its ends only, the deflecting effect of the magnet is increased in some cases 8 or ro per cent. Disturbance of this mass of filings produces a magnetic storm, which suggests that an aurora borealis is near.

The electrified magnet was placed in a glass tube having an internal diameter of about $4 \mathrm{~cm}$. The tube extended to the metal shield enclosing the needle. This metal shield was grounded. It was then found that the deflecting effect of the magnet was less, than when the magnet not connected with the influence machine. When the machine is stopped, the deflection at once becomes greater than normal, but it quickly diminishes to normal value. The reason for this was explained, by filling the tube with tobacco smoke before the machine was started. The column of air within the tube was in continual commotion while the machine was in operation. The molecules of ionized air could not then set in orderly array along the lines of force. It is remarkable that under such conditions, the permeability of the air column is less, than when the magnet is not in communication with the machine.

When the insulated magnet was enclosed in a mass of cotton batting, having a diameter of about $50 \mathrm{~cm}$., electrification of the magnet had no appreciable effect upon its deflecting effect. The fibers of cotton then appear to determine the lines along which the ionized air-filaments shall form.

While observing the needle during a wind storm in which sudden and violent gusts of wind occurred, it was observed that the vibrations were affected in a marked way at the beginning of a wind-gust. The velocity of the needle was suddenly and greatly changed. Several times it was observed that when it had come to rest at the extreme of a vibration, it would suddenly start into motion and in the direction in which it had been moving. Sometimes the velocity of swing would be greatly diminished, the motion 
would be arrested prematurely, and in the return swing, the velocity would be increased to a marked degree. These sudden changes in the motion of the needle occurred at the beginning of a gust of wind of unusual severity. In one case the unusual velocity of the wind persisted apparently unchanged for a couple of minutes, but the change in the motion of the needle occurred at the beginning of the gust. The amplitude of successive semi-vibrations would sometimes change from five minutes to half a degree, or the reverse. The amplitude was sometimes observed to gradually increase from zero to a maximum and then diminish again to zero. The maximum amplitudes were greatest when the wind was most violent and when it came in sudden gusts. On days when the wind was mild the maximum amplitude would not exceed $\mathrm{I}^{\circ}$. On days of violent winds the amplitude has often risen to $8^{\circ}$. Notwithstanding the fact that the gusts of wind occur at irregular intervals, the variations in the amplitude of the needle resemble an irregular series of beats. The needle used in these observations was formed of steel rod about $\mathrm{I} \mathrm{cm}$. in diameter and $3 \mathrm{~cm}$. in length.

These observations were made during the spring of I9I3. They were made under conditions which made conclusive results impossible. Street-cars $600 \mathrm{ft}$. distant produced disturbances of the same order of magnitude as those which were observed.

Subsequent observations made at my summer home at Hessel, Michigan, showed that coincidence of a few violent disturbances with a few of the more violent wind-gusts, was a mere chance coincidence. Tornadoes occurred in the surrounding region on two days when the disturbances were greatest, and when the winds were most violent at St. Louis. In general the results were of a character to give weight to the preliminary conclusion which the laboratory experiments with the palm-leaf fan had suggested.

The observations during the summer of $\mathrm{I}^{\mathrm{I}} 3$ were made in a large tent is $\times .20$ feet, located about 50 feet from the shore at the north end of Lake Huron. The cottage was about 200 feet distant. The village of Hessel was about half a mile to the S. E. Back from the shore was pasture land and groves of trees.

The magnetic needle was a piece of knitting wire $7 \mathrm{~cm}$. in length, suspended upon a fiber of unspun silk about $40 \mathrm{~cm}$. in length. The enclosing case was formed from a large glass bottle, 
the top of which was removed. A metal cap fitting closely around the top of the glass jar thus formed, was provided with a vertical brass tube, having at its top a torsion head and means for attaching the suspension fiber. This metal cap was sealed to the glass jar by means of adhesive rubber tape. The jar was mounted in a closely fitting base provided with leveling screws, which were about $30 \mathrm{~cm}$. apart, in order to secure stability: A fine copper wire soldered to the middle of the needle, served as a means for attaching the suspension fiber. It also extended below the needle, and to its lower end was attached a horizontal wire about $6 \mathrm{~cm}$. in length, which dipped into coal-oil in the bottom of the jar, and served as a damper for the needle. Attached to the wire suspension of the needle was a small mirror, by means of which the motion of the needle was observed, in the usual way with a telescope and scale. The scale was divided into centimeters and tenths. The scale value was I mm. $=3 \cdot 37_{-}$minutes of deflection of the needle.

The structure upon which the needle and telescope were mounted, was a frame constructed of $2 \times 4$ inch timber bolted together with brass bolts, and the legs or corner posts of the frame extended 2 feet down into clay and gravel soil. The structure was braced longitudinally and transversely, the braces being held in place by large brass screws. The structure thus formed was 8 feet in length in a north and south direction with respect to the magnetic meridian, and 4 feet in width.

The needle was deflected $90^{\circ}$ from the magnetic meridian, by means of two bar magnets 2 feet in length whose axes made an angle of $45^{\circ}$ with the meridian. The resultant field was thus the same as the horizontal component of the earth's field. This resultant field was then partly compensated by two bar magnets 4 feet in length, on either side of the needle, and at the ends of the table, about 4 feet distant from the needle: The final resultant field in which the needle was thus placed was about 0.05 that of the horizontal component of the earth's field. This was determined by the oscillation method, before the damping liquid was introduced. The time of vibration was corrected for the torsional effect of the suspension fiber. This adjustment was not maintained. Adjustment of the control magnets was occasionally 
necessary. The resultant field was certainly less than the above value during some of the work of the summer.

With this arrangement, the needle is very sensitive to changes in the horizontal component of the earth's field, and it has the advantage of permitting these changes to be observed at any instant. Some preliminary observations were made with the control magnets exposed to the air. The tent was provided with a fly, which permitted a free circulation of air between it and the roof. It however became evident that the variation in position of the needle was materially influenced by a variation in the temperature of the magnets, although the maximum temperature of the day during July and August did not exceed $85^{\circ} \mathrm{F}$. This temperature effect was greatly reduced by wrapping the magnets in heavy padded blankets. It was, however, soon eliminated by maintaining all of the control magnets at a temperature of $32^{\circ} \mathrm{F}$. This was done by placing each magnet within a piece of heavy rubber tubing. This tubing was of strong fiber, coated within and without with rubber. The ends were plugged and sealed with wax. The tubes with the enclosed magnets were mounted in $\mathrm{V}$-shaped supports within boxes put together by means of copper nails, and calked. The boxes were then filled with fragments of ice, packed closely around the rubber tubes. The ends of the boxes rested on the side timbers of the frame so that the blankets could be wrapped around the boxes. The boxes were provided with outflow tubes of brass.

The maintaining of the control magnets at a fixed temperature, diminished the daily swing of the magnetic needle in a very appreciable degree. It did not apparently affect the character of the changes due to wind-gusts and cloud shadows. It did, however, serve to remove all possible doubt from the conclusions. In this series of observations, it was not the object to make precise measurements of the quantities involved. It was a search for fundamental phenomena. For precise measurements the two sets of magnets might each be replaced by two coils as in the Helmholtz-Gaugain galvanometer. These might be mounted on a table capable of rotating around a vertical axis coincident with the suspension fiber. Two telescopes with scale mounted $90^{\circ}$ apart upon the table would serve to properly adjust the table when both circuits were open, and to deflect the needle $90^{\circ}$. The 
current in the deflecting coils would be increased until the telescope with axis east and west is directed upon the reading corresponding to the magnetic axis of the needle, as determined by the other telescope, the torsion head being turned $90^{\circ}$.

The current and the constant of the coils being known, the value of $\mathrm{H}$ is determined at that instant. The resultant field could then be decreased to any desired amount by closing the circuit containing the compensating coils, and varying the current by means of a proper resistance (carbon plates with a compression screw).

It was of course found that in general the intensity $\mathrm{H}$ of the horizontal component of the earth's field, increases during the day, reaching a maximum late in the afternoon. The numerical value of $H$ is, however, greater on clear days than on cloudy days. On days which are clear in the forenoon and cloudy in the afternoon, the maximum may occur in the middle of the day, or before noon. During days when the air is quiet, the needle is more quiet during cloudy or clear days, than when the sky is covered with small clouds with blue sky between.

On days when the wind blows in gusts at intervals of $\mathrm{I}$ or 2 minutes the needle is more unsteady in its movements than on quiet days, or on days when the wind is more uniform.

On days when gusts of wind are frequent, it is impossible to identify any particular wind-gust with any particular disturbance of the needle. The reason for this appears to be explained by an observation made on July I4. During the forenoon of that day the wind was very mild from the west. Shortly before I o'clock the wind suddenly changed to the south, while it continued at the rate of 3 to 4 miles per hour. At $\mathrm{I}$ : ro p.m. the needle began to vibrate to and fro. The scale reading at each extreme position was recorded. This was continued for 9 minutes, when a blast of wind came in from the lake to the south. It overturned a sail boat lying at a dock about 200 feet distant, the sails of which had been raised in order to dry them. It was by far the most violent wind of the summer. About 8 minutes later the wind had practically ceased, and the vibrations of the needle had also ceased. The scale reading had been under constant observation before the gust of wind began. The reading was recorded each minute, and even more frequently during times of mild disturbance, when 
slow to and fro movements made this necessary. When the movement was apparently uniform in one direction, records were made at intervals of 5 or Io minutes, although the needle was under almost constant observation. Readings were always made when the direction of motion was reversed.

During the oscillations above referred to, the watch reading was taken at as frequent intervals as was possible. In these oscillations the time of one to-and-fro vibration was about 50 seconds, as nearly as it could be determined. The time covered by consecutive vibrations frequently varied so greatly on other occasions that no precise value could be given for the time of vibration. The effect of the damping liquid was such that the needle would come practically to rest in three or four semi-vibrations when deflected $90^{\circ}$.

These vibrations above described are graphically shown in Plate VI. The instant when the blast of wind reached the observing station is indicated by the arrow, located near the middle of the group of vibrations representing this local magnetic storm. The ordinates are in scale divisions. The greatest amplitude of swing was about 20 scale divisions. The hour of the day is laid off upon the horizontal axis. The fact that the needle was affected by this air disturbance south of the station at least 9 minutes before it reached the station, is in exact harmony with the suggestion given in a paper in the Transactions of the Academy of Science of St. Louis and above discussed. As was there pointed out, a brush which disturbs iron filings at any point on a plate of glass above a bar magnet, is producing an ether disturbance in the field of that magnet. This observation also shows clearly, why it is that on stormy days, when gusts of wind follow each other at frequent intervals, the effect due to any gust cannot be identified. At any instant, the needle responds to a summation of these disturbances. An inspection of Plate VI will show that the disturbing effect of this gust of wind probably began at about I $2: 55$, or about 24 minutes before it reached the station. This was the time when the wind changed in direction.

It could hardly be expected that such a wind disturbance could produce a magnetic storm of more than a local character. But it is not at all improbable that tornadoes and tropical cyclones may produce much more widespread effects. A wind disturbance 
among the atmospheric ions which accumulate along the magnetic lines of force at or near the earth's magnetic poles, might be expected to produce the effects which have long been observed.

We need not consider the source or origin of this electrification at the magnetic poles of the earth. It is enough for us to know that it exists. Its effect upon the magnetic field of the earth is similar to that produced by masses of iron filings, applied to the ends of a bar magnet, on the field of that magnet.

A wind disturbance here would produce a magnetic storm over a vastly greater area than would a similar wind storm in lower latitudes. A wind-storm progressing in an easterly direction around and near one of the magnetic poles of the earth might produce progressive easterly disturbances in lower latitudes such as have been discussed by Bauer. The velocity of progression of such a magnetic storm as observed in lower latitudes, would depend upon the nearness of the wind disturbance to the magnetic pole.

On ten or twelve occasions magnetic storms were observed, which were caused by a local dash of rain. When rain falls continuously or at intervals during a day when the sky is covered with clouds, which extend over adjoining states, the needle shows no appreciable disturbance. The horizontal component of the earth's field is then much weaker than it would be if the sky were clear, but there is no additional change due to a rainfall. The limiting condition has been already reached.

When small clouds are scattered over the sky and a local fall of rain occurs at the observing station, the sunlight passing through the air through which the rain-drops fall, a very marked magnetic storm is produced. Such a disturbance is represented in Plate VII.

This rain, which was very violent, began while $I$ was at the noon-day meal. It lasted about ro minutes. When the tent was reached the rain had practically ceased at the station. The sun was visible during most of the time while the rain was falling. The area covered by the rain was probably not over I or 2 square miles. Its boundary could be seen upon the lake to the south, while I was on the way to the tent. The needle showed that we were then in the midst of one of the most violent magnetic storms of the summer. The vibrations ceased about 5 minutes 
after observation began. The extreme reading of the scale for each oscillation was taken. They are represented in Plate VII, together with subsequent readings of the needle represented on the same time scale. Readings made before leaving the tent for lunch are also shown. The gap between the readings before and after lunch is only in part represented, as is indicated by the figures at the bottom of the plate representing the hour of the day. The needle was in a more disturbed condition after the vibrations had ceased than it had been before. Evidently the rain had some effect upon the magnetic field at the station, when it was falling through air to the south of the station, and had ceased at the station. The needle was damped during this day, so that summation effects were impossible, nevertheless in one of these oscillations the needle vibrated through an arc of over $5^{\circ}$.

This rain occurred on August 26. A diagram representing the movement of the needle between ro a.m. and sunset on that day, is represented in Plate VIII. The vibrations due to the rain occurred at the close of the first gap in that curve. They cannot be properly represented here with the time-scale used in this plate. They are replaced by a straight line. The second gap in the diagram represents the time required to finish the noon-day meal, which had been interrupted by the rain. The part of the diagram of Plate VII, after the hour of $\mathrm{I}: 05$, is the part which in Plate VIII lies between the two gaps.

Plate VIII also represents the effect upon the horizontal component of the earth's field, of two large dense and sharply defined clouds passing over the sun. Their effect is shown at points corresponding to II:IO a.m. and 4:28 p.m. During seven weeks the needle had been under constant observation, from sunrise to sunset, in order to secure the results which were here obtained. On many days evidence of cloud effects were observed which seemed conclusive, but usually the edges of the cloud would not be sharply defined. In some cases the edges would be more or less transparent, in some cases small clouds of irregular form would surround the larger cloud. It often happened that large dense clouds appeared to be approaching the sun, and the needle gave results which were wholly different from those which had been expected. On going out of the tent it would be found that the cloud had behaved in a wholly different manner from what had been expected. 
In some cases it practically disappeared before it reached the sun. Sometimes it was dispersed into smaller clouds, which were more or less hazy in outline. Their effect was often appreciable and persuasive, and yet more or less unsatisfactory.

The fact that it was impossible to predict at what moment the desired conditions might present themselves, and the necessity for having a record of the behavior of the needle for a considerable time interval before the sun entered a dense cloud, made it necessary to keep the needle and the clouds under constant observation, recording the results during each minute of the day, sometimes at lesser intervals, so far as this was possible. The only interruption to this work during July and August was from August I2 to 16 , during which interval a severe attack of a painful illness made work of any kind impossible.

The sun entered the well-defined edge of the first cloud above referred to at Io: 45 a.m. The needle had been previously moving continuously in a direction such as would be caused by a steady increase in the strength of the field. When the sun entered the cloud, irregularities in the movement of the needle were observed. The air on the border of a cloud shadow often gave evidence of a disturbed condition. In this case the sun was in the center of the cloud at about II:OI. This cloud then covered the overhead sky down to about $45^{\circ}$ from the horizon. Below this cloud the sky was clear. The sun reappeared at II h. I $2 \mathrm{~m} .30 \mathrm{sec}$. At this time the scale reading corresponded to the minimum shown in the diagram, Plate VIII. The needle at once reversed its direction of movement. The reading at II:40 or II:50 was, as the diagram shows, about what it would have been if the cloud had not appeared.

This cloud was soon afterward broken up into smaller clouds, and other smaller clouds appeared. From i 2:30 to 2 p.m. the sky was partly covered here and there by smaller clouds, so that at the station, as at surrounding points, the sun was visible at and during frequent intervals. One of these small clouds unexpectedly gave rise to the dash of rain before discussed. The general effect of these clouds is shown in the general drop in the curve between I $2: 30$ and $\mathrm{I}: 30$ p.m.

The sun entered another dense and sharply defined cloud surrounded by clear sky, at 4:20 p.m. of this same day, after the 
daily maximum had been passed. It emerged from this cloud at 4:28 p.m. While the sun was hidden by this cloud, the intensity of the magnetic field diminished as in the other case, as is shown by the drop in the curve. When the sun reappeared the intensity at once began to increase. At 4:37 the reading was that corresponding to the general trend of the curve during that afternoon. The time of entering and leaving the cloud is in both cases indicated on the diagram by arrows.

It would thus appear that cloud shadows during the day have the same effect upon the earth's magnetic field that the earth's shadow has at night. The lines of the field sway around them. They sway above the clouds into the sunlight. The horizontal component would thus be diminished below the clouds.

It is impossible to present here the full evidence obtained, which to me seems to establish beyond all question the conclusion that local variations in the earth's magnetic field are determined wholly by local weather conditions. It is contained in 300 pages of closely written notes on pages 8 inches square. While it might at first seem that the greater part of this record was of no importance, it does establish the general conclusion that when local conditions were uniform, whatever they might be, the magnetic needle showed no marked disturbance of an abrupt character, such as we have in these vibrations.

It may suffice to discuss briefly the record of July ig. In doing this the weather maps kindly furnished by the Weather Bureau at Washington were of material assistance. On the afternoon of this day, the needle showed more disturbance than on any other day. At io a.m. a rain cloud was observed in the southern horizon. At II:45 the needle began to vibrate, the average amplitude of vibration being about 20 scale divisions, and sometimes reaching 35. The wind, which had been from the northwest, had changed to the south. This continued until about I 2 : Io p.m., when the needle became less disturbed, and observations ceased until I $2: 45$ p.m. During this disturbance, it could be seen that a rain was falling on the lake to the south. At $\mathrm{I} 2: 45$ a violent dash of rain began, which continued for ro minutes, and then continued as a milder rain until $\mathrm{r}: 05$. The clouds were not continuous over the sky. The sun appeared at intervals.

The point of importance is that these vibrations began and 
continued for an hour, while a rainstorm existed to the south of the station. During the remainder of the afternoon periods of sunshine and rain came in alternation. Between $2: 37$ and $3:$ Io over half an inch of rain fell, from what appeared to be a local cloud. The needle continued to vibrate during this rain, and after it had ceased at the station and while its roar could be heard upon the lake to the south. The wind was very mild during the entire day, its velocity not at any time exceeding 8 or Io miles per hour. The amplitude of the vibrations sometimes reached 40 scale divisions. The greatest amplitude of the day was 49 scale divisions. The needle was damped during this day.

The data given on the weather map show that the rain which visited the observing station extended from Escambia, which is in northern Michigan, near the north end of Lake Michigan, to Alpena, which is in southern Michigan, near the north end of Lake Huron. At the former station the rainfall was 0.44 inch and at the latter it was 0.36 inch. At Saginaw, Mich., which is south of Alpena and also on the west side of Lake Huron, the rainfall was 0.26 inch. At Sault Ste. Marie, at the outlet of Lake Superior, no rain fell. This rainstorm was a purely local one, extending across the head of Lake Michigan and along the straits of Mackinac, and probably into Lake Huron.

On July I6, 26, 27 and 3 I similar local rains occurred in the same region during the midday hours. In some cases there was practically no rainfall at Hessel, but the clouds which were observed near the horizon were recognized as rain clouds. The weather maps show that rain fell at surrounding weather stations. On all of these days, the needle was in to-and-fro vibration at intervals during the day. In all cases when the weather maps show rains in this region, which occurred during the hours of observation of the needle, the needle showed such vibrations.

On three days they were observed when violent gusts of wind occurred at the station, with no rain in that part of the country.

On August 23, very marked and sudden changes in the position of the needle were observed, and they were so unusual as to lead to the suspicion that something unusual must have happened. There were no vibrations accompanying those disturbances. The day was unusually clear. Very light rains occurred at all of the nearest weather stations, the greatest fall, 0.20 inch, being at 
Houghton, about 200 miles distant in a direction a little north of west.

On August 8, a violent rain accompanied by a continuous roar of overhead thunder occurred between 4 and $6: 30$ a.m. The needle was then very quiet, as was the case on every morning of the summer with one exception. On this morning when a few oscillations occurred after sunrise, they were accompanied by violent gusts of wind.

On two or three occasions results were observed which suggested that winds from the north, reaching the station through a grove of trees, had a slightly different effect from that of a wind from the lake. This subject requires additional attention.

Perhaps the most interesting phenomenon observed during the summer was the continuous vibration of the needle during a period varying from half an hour to two hours preceding sunset. This was observed on nearly every evening when the western sky was clear. The vibrations were greatest when the day had been clear, and the intensity of the field had reached a high maximum. They did not occur when the afternoon sky was covered with a dense cloud. The cloud shadow is then joined to the earth's shadow. They did not occur in the morning, either before or after sunrise. Observations were sometimes begun as early as 2 o'clock a.m. They were usually begun about an hour before sunrise.

Plate IX, made from observations on August 3I, gives an illustration of these sunset disturbances. The plate shows how the needle moved during the afternoon, before the oscillations suddenly began. In the original drawing, this part of the curve was drawn to a time scale of $6 \mathrm{~cm}$. per hour. For the period during which the oscillations are represented, the time scale is $6 \mathrm{~cm}$. to about 3 minutes. One to-and-fro oscillation was drawn to each half-centimeter. During this day the damping liquid had been removed. It will be observed that the disturbing cause ceased at about $5: 45$ and the needle gradually came to rest. On this day two similar violent disturbances occurred subsequently before sunset, which are not represented in Plate IX. The greatest amplitude reached was about 250 scale divisions, or about $14^{\circ}$ of arc. The extreme scale reading for each and every vibration was read.

In nearly all of the observations on this sunset disturbance, 
the motion of the needle was restrained by the damping fluid. The amplitude of the vibrations was then in general over an angle not exceeding 50 scale divisions or 2.8 degrees. The time of vibration was practically the same whether the damping fluid was used or not. It was not uniform in either case. The vibration of the damped needle frequently continued without cessation for an hour or more. At this hour of the evening there was usually no wind at the station.

It is evident that along what may be called the sunset meridian, there will generally be places where cloud shadows are joined to the earth's shadow. Since only the horizontal component of the earth's field of force is effective in action upon the needle, we may consider the conditions which would exist in a field of force in which the lines are horizontal. Where the clouds occur, these lines tend to sway above the clouds into the sunlight. If we consider these lines to behave like elastic threads, they are elongated by this distortion. They snap asunder and disappear as they are thus distorted and forced toward the approaching shadow of the earth, the field diminishing in strength in a rhythmical way. This statement must be considered as figurative in character, but it is in a certain sense descriptive of the observed phenomena. It is with some surprise that I find that this sunset disturbance has not been observed at stations where continuous records are made. This conclusion obtained from an examination recently made of government publications has been confirmed by information just received from the Chief of the U. S. Coast and Geodetic Survey. Evidently the subject deserves additional attention. It is evident that this is the high sea with which wireless messages are contending in what is called the sunset effect.

It is also evident that local changes in magnetic permeability are the causes of local magnetic storms. Local rains, wind-gusts and cloud shadows in air which has been ionized by solar radiation bring about what is called the day effect in wireless telegraphing. It has long been known that a public speaker can be heard most distinctly, when other sources of sound waves are not simultaneously active in the audience which he addresses.

It will of course be understood that the fact that wind-gusts a few miles distant are found to affect a magnetic needle, is in 
harmony with the well-known fact that solar disturbances also affect it.

The observation of Young at Sherman, Idaho, on August 3, I872, showed that a solar outburst produces electro-magnetic waves, which travel with the velocity of light. ${ }^{1}$ The effect on the magnetic needle at Greenwich and Stonyhurst was recorded at the same instant, that a solar disturbance was observed by Young (within the instrumental errors). Such results should lead us to expect that wind-gusts in air ionized by sunlight or by solar dust, as has been pointed out by Arrhenius, should produce similar results of a more local character.

In 1823 , Barlow ${ }^{2}$ made an experimental study of the diurnal variation of the earth's magnetic field. He deflected the needle into an east and west position, by means of two control magnets, lying in the magnetic meridian, acting upon opposite ends of the needle. At his request, his associate, Christie, continued the work. The effect of the earth's field was in part compensated by a magnet parallel to the dip needle. Their papers are in sequence in the Phil. Trans. of the Royal Society for I823. Barlow gives his conclusion as follows:

"It appears to me that the quantity of daily change depends in a greater degree on the intensity of the solar light, than on the mere temperature of the day, although it is certain from some recent experiments of Mr. Christie, that the change of temperature of the air during the day, has a much greater effect upon the intensity of the opposing magnets than I could possibly have imagined."

Christie varied the temperature of the control magnets by placing upon them paper moistened with cold and with hot water. He concluded from the effect thus produced upon the magnets, that temperature, if not the only cause, is the principal cause of the daily variation in the earth's field.

A part of the work of both Barlow and Christie was done in their gardens, and the remainder in their houses, which were about a mile apart. Both found great differences in the daily

${ }^{1}$ The Sun. By Young, p. 158.

${ }^{2}$ Barlow should not be forgotten. He was the first to make an electric motor. Barlow's wheel is the rotating armature of an electric motor. Eight years later Faraday reversed this toy motor, and produced the first electrical generator. Neither of these men realized what he had accomplished. 
variation indoors and in open air, and various possible causes for it are discussed. Barlow concludes that it is probably due to the cause discovered by Christie, although well known before his time, that the intensity at any point in the field of a bar magnet depends upon the temperature of that magnet. He ascribes this difference to the different temperature conditions of the control magnets. Nevertheless he is of the opinion that the quantity of daily change in the earth's field depends in a greater degree upon the intensity of solar light, than upon the mere temperature of the day. Evidently his intuitive faculty was of a high order.

Barlow's conclusion did not carry with it any rational explanation of causes, since at that time ionization of the air, by sunlight, resulting in an increase of its permeability, was unknown. The work of Christie also raised a doubt in the minds of others. Subsequent writers seem to have found it necessary to say that the daily variation and local magnetic storms had not been satisfactorily explained.

On January 27, I831, Barlow presented a paper to the Royal Society. In this paper he refers to the discoveries of Oersted, Ampère and Seebeck. He refers to the work of Seebeck as another link in the chain of evidence, that "terrestrial magnetism is purely an electrical phenomenon, deriving its origin during the diurnal revolution of the earth from the action of the sun's rays in successive portions of its surface, in directions parallel to the equator."

He describes in this paper, a model illustrative of his ideas at that time. It was a sphere of wood in which were laid conducting wires, lying in grooves along parallels of latitude. Electric currents in these wires produced around the sphere a magnetic field like that of the earth.

During the last fifteen years the present writer has made various attempts to produce a local magnetic storm in the earth's field by means of small amounts of high power explosives. The results discussed in the present paper seem to indicate beyond question that such explosions are capable of producing magnetic disturbances. The effect of the gust of wind shown in Plate VI was to produce an ether disturbance extending far beyond and in advance of any air waves, or air disturbance.

Recent experiments with dynamite on the grounds adjoining the buildings of Washington University have not given conclusive 
results. It is difficult to eliminate other disturbances, and it is not permissible to use as large a quantity of the explosive as will probably be necessary. It is hoped that this work may be continued at Hessel during the summer of I9I4. It seems probable that a disturbance of this kind, originating in ionized air, should be capable of producing an effect on the receiving apparatus of a wireless station.

As this volume is about to be published, I learn through the courtesy of the Chief of the U. S. Coast and Geodetic Survey, that Bauer has announced that the local effect of the moon's shadow during a solar eclipse, upon the magnetic field of the earth, was similar to that of the earth's shadow at night. The correctness of this conclusion is beyond all doubt. Nevertheless this work should be repeated during future eclipses, with more sensitive instruments than have been heretofore used. It seems evident that we can now explain the causes not only of local magnetic storms, but also the causes of the daily and annual variation of the magnetic field of the earth. 


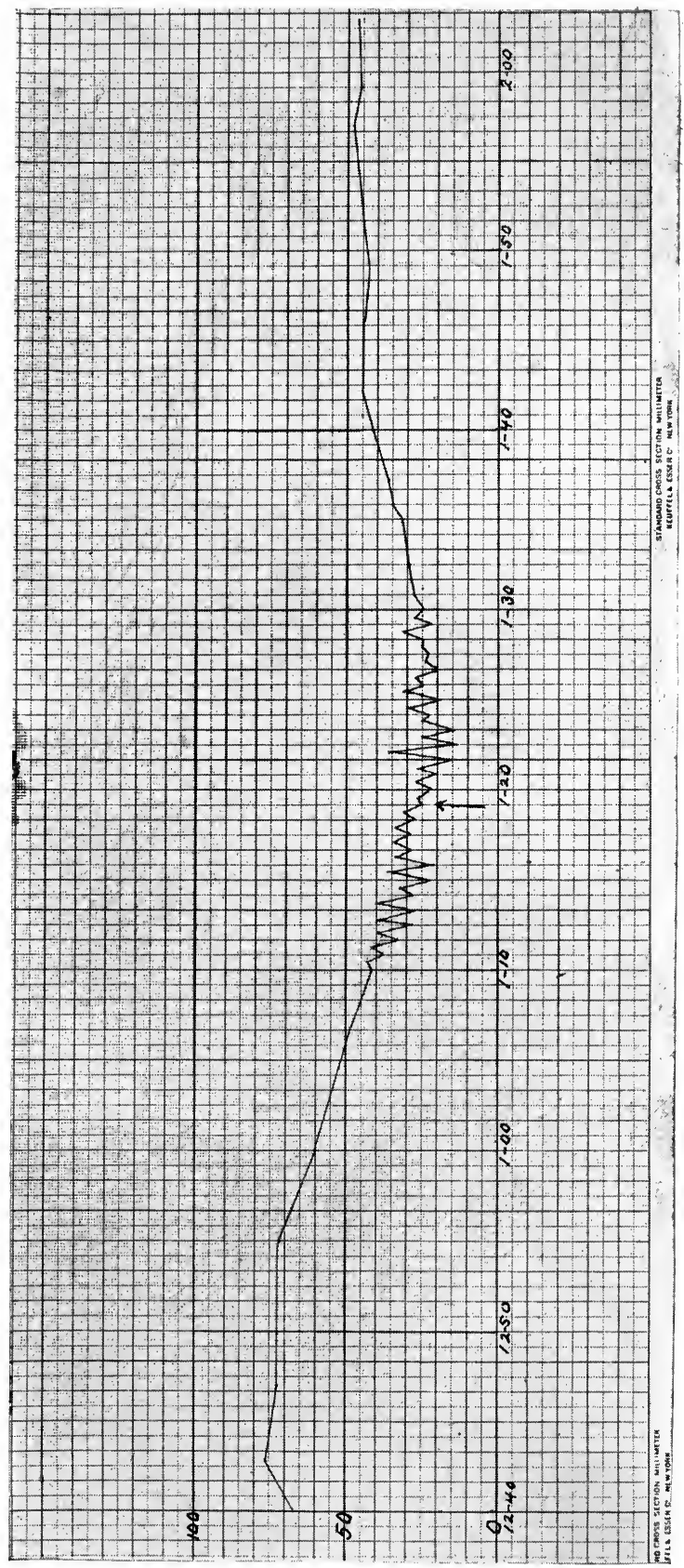

Plate VI.-Magnetic Storm Due to Wind. 


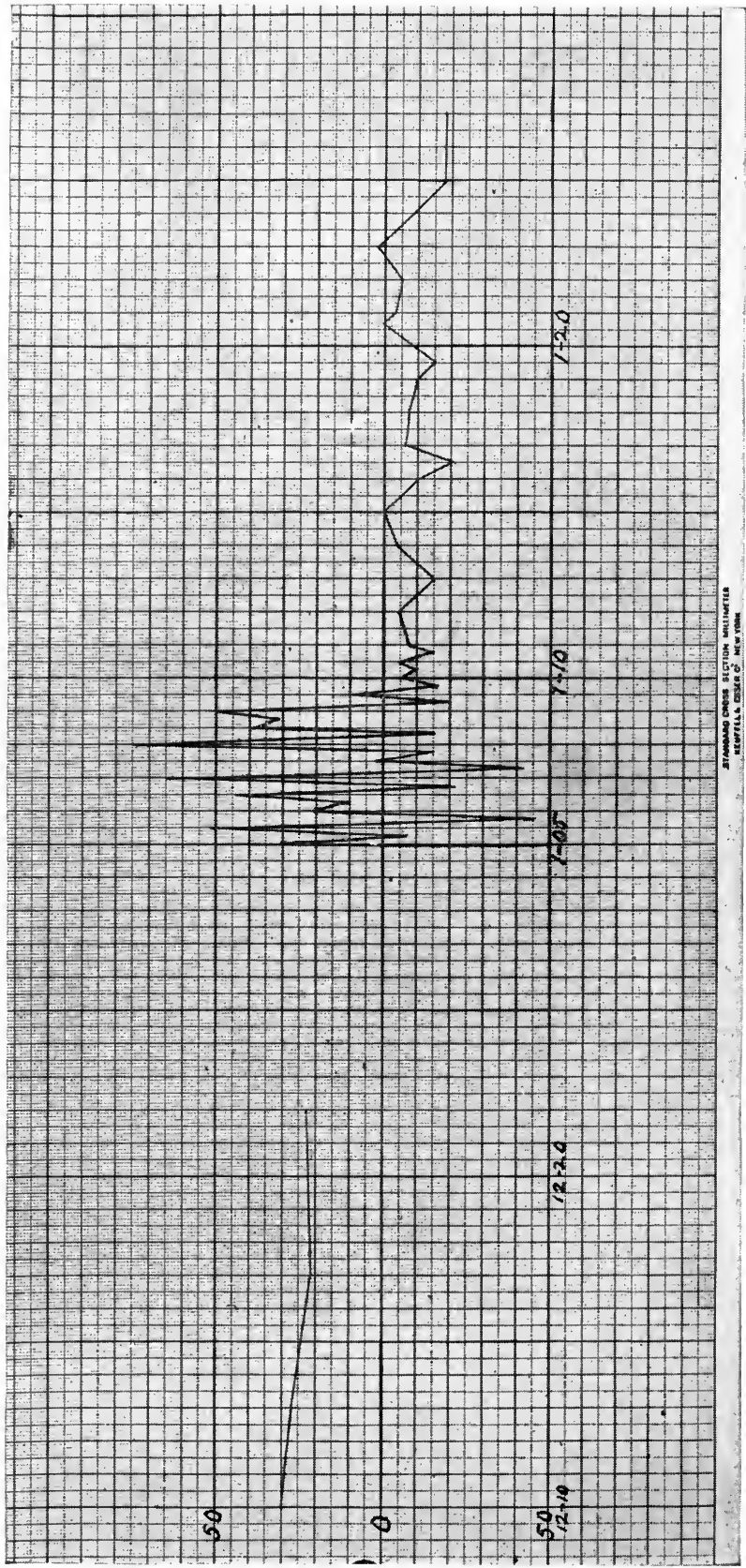

Plate ViI.-Magnetic Storm Due to Rain. 


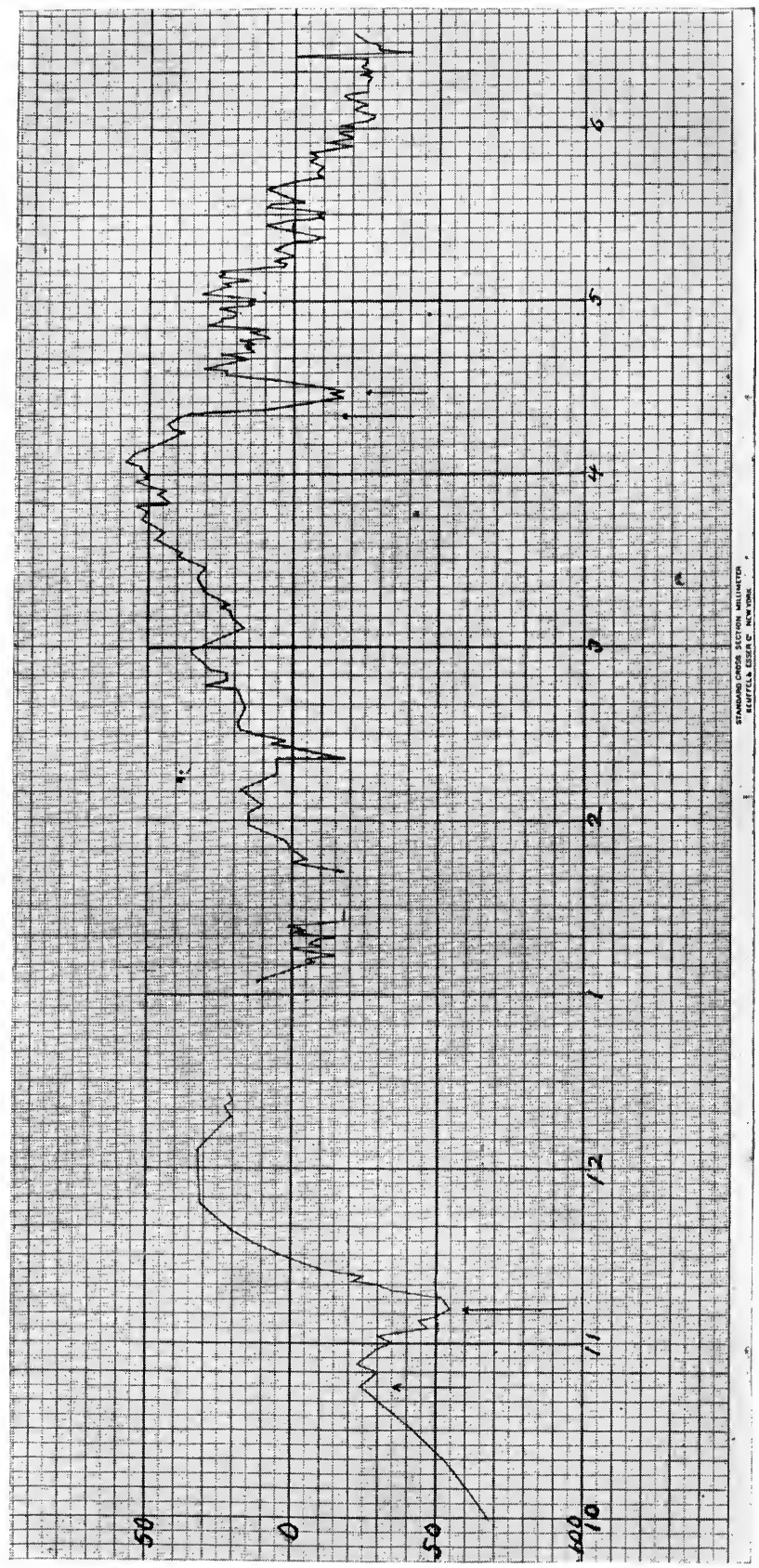

Plate Vili.-Effect of Cĺoud Shadows. 


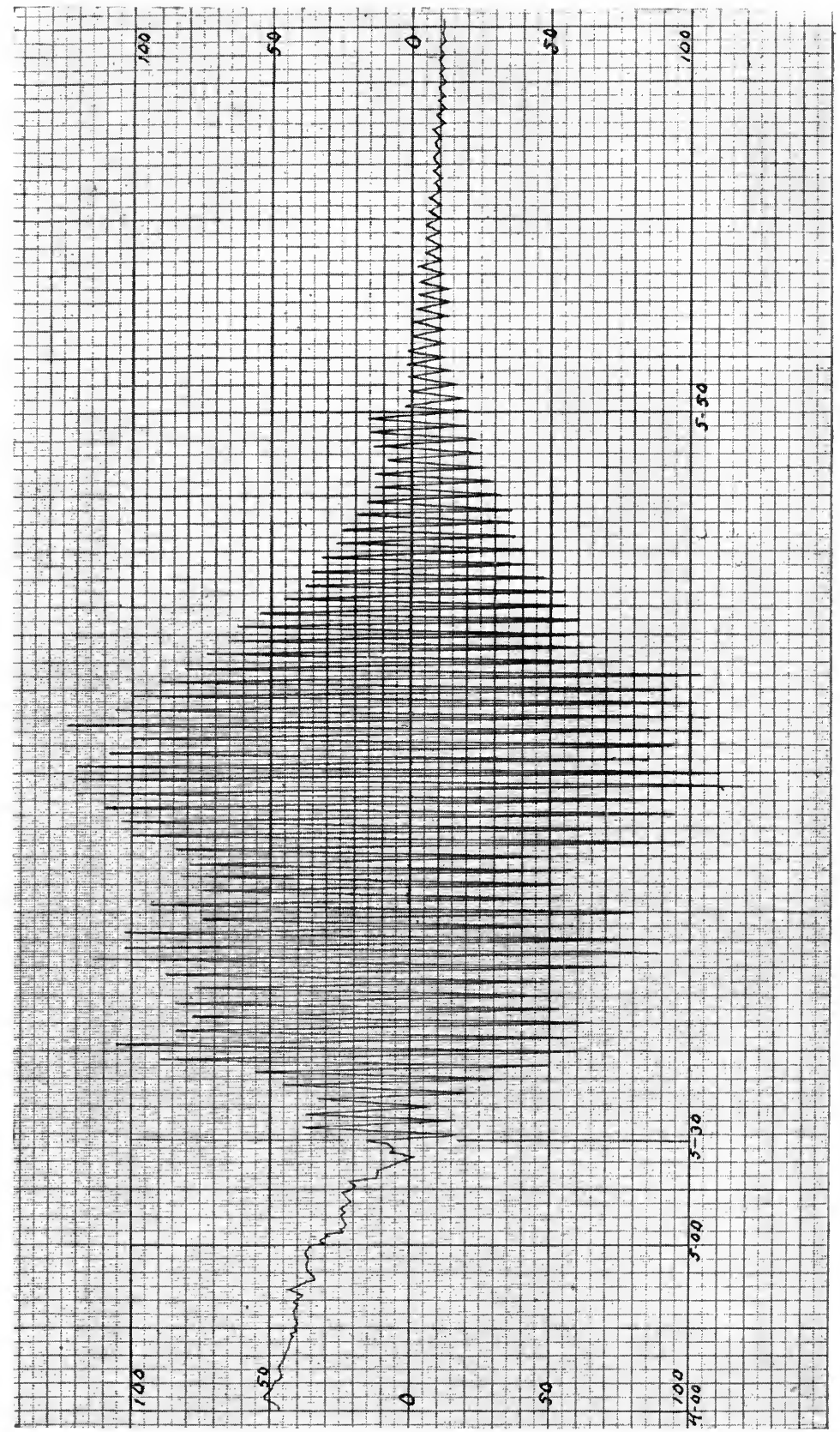

Plate IX.-Magnetic Storm at Sunset. 


\section{INDEX}

After-effects, 40, 4I

Arc discharge, 26

Attraction between masses, 19

Aurora borealis, 59

Ball-lighting effects, $35-37$

Barlow, work of, 66,67

Bauer, effect of moon's shadow, 68 progressive magnetic storms, 59

Becquerel, Edmund, on buckling of wires, 48

Canal rays, $5,6,7$, Io

Christie on temperature effects, 66

Cloud shadows, their magnetic effect, $60-62$

Conduction in gases, $13,14,25,26$

Critical spark length, 26

Crookes dark-space, 24

Dark and luminous columns in multiple, 24-26

discharge, 3,6

De Nelis, on electrical explosion, 20

Disruptive discharge, conditions for, I I, I 2, I 5

effect of paper in preventing, ro

effect of metal sheet in preventing, II

path of, IO-I4

Drainage column, 9 , Io, 24

lines, $\mathrm{I}_{4}, \mathrm{I}_{5}$

steamers, 7,8

Early history, 66-68

Electrical convection, 26, 38

Evaporation of electrified water, 50

Explosive condition of matter, $19^{-23}$

Faraday dark-space, 24, 25

Fatigue effects, 40, 4I

Hittorf tube, 26

High potential lines, 27-34

Inflow of negative corpuscles, 32-34

Lighting discharges, I6, I7

Local variations and local weather, 62, 65

Magnetic disturbance due to clouds, $60-62$ station, equipment of, $54-56$ storm, artificial, 52, 53
Magnetic disturbance, due to rain, 60 due to wind, 58,59 at sunset, 64,65

storms and weather, 62,63

Maxwell on velocity of electricity, 4I

Negative glow, 2, 5, 24

Newton's law for attraction, 19,20

Oscillations, electrical, 5, 6, 47

Palm-leaf fan, magnetic storm produced by, $5^{2}$

Paper strip obstructs the positive column, ro

prevents passage of spark, Io

Pendulum, the electrical, r

Permeability and atmospheric disturbance, 53

Positive column, 5 , 10, I2, I8

Pumping service, electrical, $42-44$

Rain, magnetic storm due to, 59, 62

Rowland effect, the, 38 reversed, 39

Shadow images, 40, 4I of the moon in eclipses, magnetic effect of, 68

Shadows in the positive column, 9

Shield of metal in the positive column, $2,3,5,6$, I I

Singer on electrical explosion, 20

Solar outbursts and magnetic storm, 66

Steam, decomposition of, 48,49

Striæ, electrical, 47

Sunset disturbances, 64

Thomson, J. J., suggestions of, 25

Universal repulsion, 24

Vapor of water, decomposition of, 48,49 Velocity of corpuscles in a conductor, $4 \mathrm{I}, 45,46$

Wind-gusts, magnetic disturbance due to, $52,54,58,59$

Wind-mill, electrical, 2, 5, 7

Wireless telegraphing and magnetic disturbance, 65

and the sunset effect, 65

Young, his reference to solar outbursts and magnetic storms, 66 

THIS BOOK IS DUE ON THE IAST DATE STAMPED BELOW

AN INITIAL FINE OF 25 CENTS WILL EE ASSESSED FOR FAILURE TO RETURN THIS BOOK ON THE DATE DUE. THE PENALTY WILL INCREASE TO $5 O$ CENTS ON THE FOURTH DAY AND TO \$1.00 ON THE SEVENTH DAY OVERDUE.

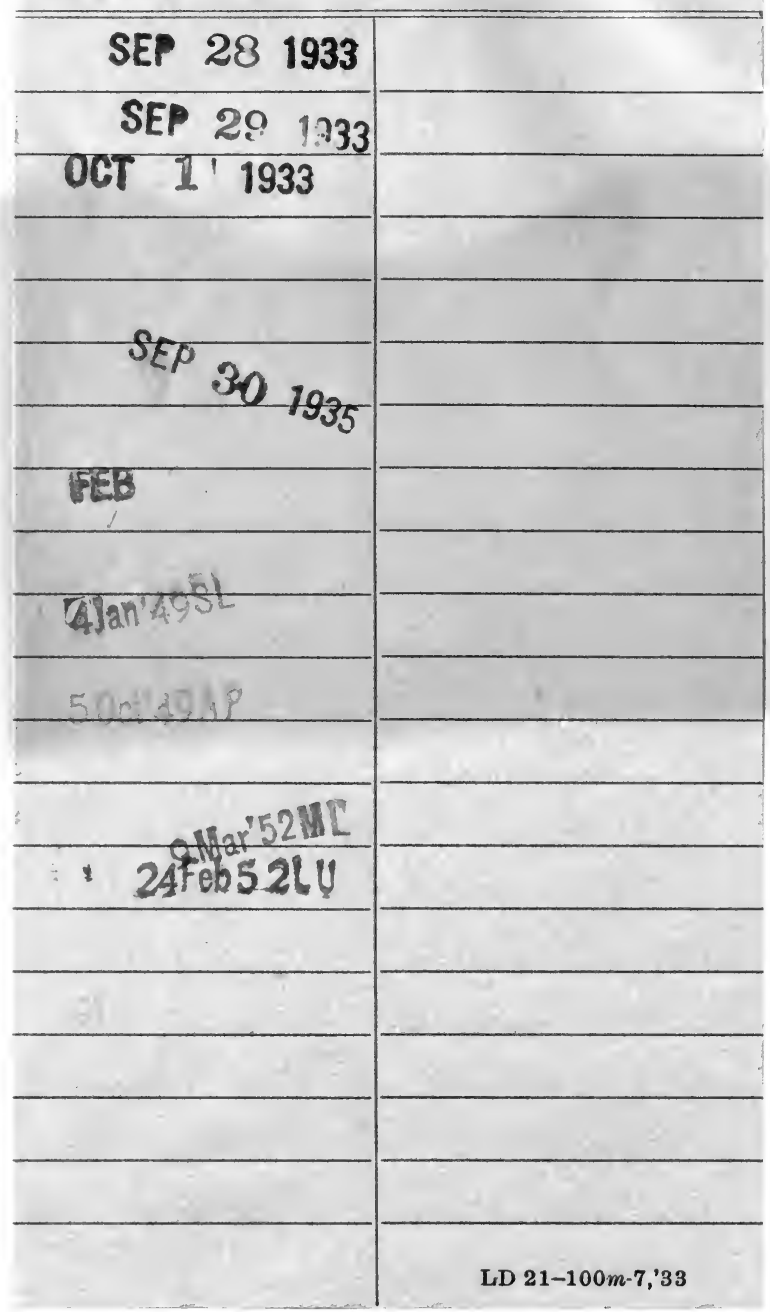


ore hat

๑.

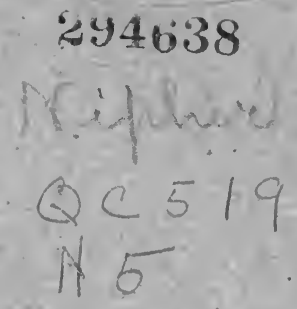

UNIVERSITY OF CALIFORNIA LIBRARY 
